\title{
Excessive disgust caused by brain lesions or temporary inactivations: mapping hotspots of the nucleus accumbens and ventral pallidum
}

\author{
Chao-Yi Ho and Kent C. Berridge \\ Department of Psychology, University of Michigan, 525E University Street, Ann Arbor, MI 48109-1109, USA
}

Keywords: brain reward system, food intake, hedonic, limbic, ventral forebrain

\begin{abstract}
Disgust is a prototypical type of negative affect. In animal models of excessive disgust, only a few brain sites are known in which localized dysfunction (lesions or neural inactivations) can induce intense 'disgust reactions' (e.g. gapes) to a normally pleasant sensation such as sweetness. Here, we aimed to map forebrain candidates more precisely, to identify where either local neuronal damage (excitotoxin lesions) or local pharmacological inactivation (muscimol/baclofen microinjections) caused rats to show excessive sensory disgust reactions to sucrose. Our study compared subregions of the nucleus accumbens shell, ventral pallidum, lateral hypothalamus, and adjacent extended amygdala. The results indicated that the posterior half of the ventral pallidum was the only forebrain site where intense sensory disgust gapes in response to sucrose were induced by both lesions and temporary inactivations (this site was previously identified as a hedonic hotspot for enhancements of sweetness 'liking'). By comparison, for the nucleus accumbens, temporary GABA inactivations in the caudal half of the medial shell also generated sensory disgust, but lesions never did at any site. Furthermore, even inactivations failed to induce disgust in the rostral half of the accumbens shell (which also contains a hedonic hotspot). In other structures, neither lesions nor inactivations induced disgust as long as the posterior ventral pallidum remained spared. We conclude that the posterior ventral pallidum is an especially crucial hotspot for producing excessive sensory disgust by local pharmacological/lesion dysfunction. By comparison, the nucleus accumbens appears to segregate sites for pharmacological disgust induction and hedonic enhancement into separate posterior and rostral halves of the medial shell.
\end{abstract}

\section{Introduction}

The positive hedonic impact of reward is crucial to normal daily function. In the absence of positive hedonic impact, anhedonia (loss of positive affect) or dysphoria (excessive negative affect) can characterize clinical affective disorders in humans.

A prototypical form of negative affect is disgust. Excessive disgust can occur in anxiety disorders, phobias, anorexia nervosa, and obsessive-compulsive disorder (Sprengelmeyer et al., 1997; Cisler et al., 2009; Olatunji et al., 2010; Weygandt et al., 2012). Sensory disgust has been suggested to be the prototypical and original form of this negative affect, but disgust is also a potentially complex negative emotion, and can occur as higher disgust, such as moral or aesthetic disgust. Both levels have been suggested to share the same evolutionary roots, and to have overlapping neural substrates that arose originally to mediate the sensory disgust in response to unpleasant tastes and smells (Rozin, 2000; Calder et al., 2001; Zald et al., 2002; Chapman \& Anderson, 2012; Rozin \& Haidt, 2013; Tybur et al., 2013).

Correspondence: Kent C. Berridge, as above.

E-mail: berridge@umich.edu

Received 2 May 2014, revised 8 August 2014, accepted 13 August 2014
Affective neuroscience experiments using animals have helped to identify particular brain sites that can causally enhance the positive hedonic impact of sensory rewards, such as sweetness (Baldo \& Kelley, 2007; Smith et al., 2010; Richard et al., 2013a). In particular, two interactive 'hedonic hotspots' have been identified as cubic-millimeter subregions: one in the nucleus accumbens (NAc), in the rostrodorsal quadrant of the NAc medial shell), and another in the ventral pallidum (VP), in the posterior half. In these NAc or VP hotspots, stimulation with opioids or related neurochemicals causes increases in the positive hedonic impact of sweetness, measured as increased positive 'liking' reactions to sucrose (Peciña \& Berridge, 2005; Smith \& Berridge, 2005; Ho \& Berridge, 2013; Castro \& Berridge, 2014). 'Liking' here refers to objective orofacial expressions (e.g. lip-licking) that are typically elicited by sweet tastes, which in rats are homologous to positive affective facial expressions elicited by sweetness in human infants and other primates (Steiner, 1973; Pfaffmann et al., 1977; Grill \& Norgren, 1978a; Berridge, 2000; Steiner et al., 2001). Conversely, negative sensory 'disgust' reactions are elicited by bitter tastes (e.g. gapes, headshakes, and chin rubs).

Do hedonic hotspots also play a special role in generating the excessive disgust that occurs under neuropathological conditions? Conceivably, neural dysfunction in hedonic hotspots might facilitate disgust, by impairing the capacity for opposing positive hedonic 
impact. Alternatively, disgust could arise from pathological dysfunction in separate brain sites, independently of hedonic-enhancing hotspots.

So far, hedonic hotspots of the NAc and VP have been defined primarily by their capacity to enhance sensory liking reactions, or to produce a gain of function for positive hedonic impact. Here, we conversely examined the roles of these hotspots and nearby sites in producing a loss of positive hedonic function after brain lesion or inactivation, and replacing 'liking' with excessive negative sensory 'disgust', and compared their roles with those of other nearby subregions or structures, such as the lateral hypothalamus (LH) and extended amygdala (Teitelbaum \& Epstein, 1962; Cromwell \& Berridge, 1993; Swanson, 2005; Zahm, 2006; Inui et al., 2007; Heimer et al., 2008; Thompson \& Swanson, 2010; Zahm et al., 2013).

\section{Materials and methods}

Specifically, we focused on mapping the replacement of positive 'liking' reactions to sweetness with intense negative 'disgust' reactions (e.g. gapes and headshakes) produced either by local excitotoxin lesions or by temporary pharmacological GABA inactivation of subregional sites in those structures. The affective taste reactivity test was used to assess affective 'liking' and 'disgust' orofacial reactions (Fig. 1), and to identify which sites of damage or inactivation in forebrain regions caused positive hedonic reactions that are normally elicited by sweet tastes to be replaced by negative reactions such as gapes or headshakes.

Either permanent excitotoxin lesions or temporary inactivations by GABA agonist microinjections were performed bilaterally in rats, targeted at sites in either: (i) the VP; (ii) the medial shell of the NAc; (iii) the LH; or (iv) the extended amygdala (e.g. the bed nucleus of the stria terminalis). Sites were scattered across rats so as to fill targeted brain structures sufficiently for functional mapping, but kept as identical as possible within each rat's bilateral placements, so that each rat individually contributed symmetrical dysfunction at a particular bilateral site. Subregional sites were mapped histologically and specifically compared for behavioral effects on affective taste reactivity and on food intake. All experimental procedures were approved by the University Committee on the Use and Care of Animals at the University of Michigan, and were carried out in accordance with the guidelines on animal care and use of the National Institutes of Health of the USA.

\section{Surgery}

Rats (total, $n=113$; VP, LH and extended amygdala sites, $n=94$; NAc, $n=27$ ) were anesthetized either with ketamine for microinjection cannula implantation, or with methoxyflurane for excitotoxin lesions $(80 \mathrm{mg} / \mathrm{kg}$ ketamine $\mathrm{HCl}, 10 \mathrm{mg} / \mathrm{kg}$ xylazine, and $0.5 \mathrm{mg} /$ $\mathrm{kg}$ atropine sulfate; halothane induction in a chamber, followed by methoxyflurane during surgery inhaled through a ventilator system). Anesthetized rats were placed in a stereotaxic device with the mouth bar set either to flat for VP, LH and extended amygdala rats, or to $+5.0 \mathrm{~mm}$ above intra-aural zero for NAc rats. VP group coordinates were: anteroposterior (AP) from 0 to $-1.2 \mathrm{~mm}$ relative to bregma; mediolateral (ML), $\pm 3 \mathrm{~mm}$; and dorsoventral (DV), $-5.5 \mathrm{~mm}$. NAc group coordinates were: $\mathrm{AP}$ from +2.4 to $+3.4 \mathrm{~mm}$ ahead of bregma; ML, $\pm 1.0 \mathrm{~mm}$; and DV from 5.7 to $6.0 \mathrm{~mm}$ below the skull. $\mathrm{LH}$ and extended amygdala (bed nucleus of the stria terminalis) group coordinates were: AP from -1.2 to $-1.8 \mathrm{~mm}$ behind bregma; $\mathrm{ML}, \pm 2.0 \mathrm{~mm}$; and $\mathrm{DV},-8.0$ to $9.1 \mathrm{~mm}$. Left and right bilateral coordinates were always identical to preserve symmetry within the same rat. Individual placements were staggered across rats so that these placements covered the structure or region of a structure (e.g. entire medial shell). Bilateral sites for excitotoxin infusions were always directly in the brain target, whereas sites for drug guide cannulae were always $2.5 \mathrm{~mm}$ above the target (23-gauge, for subsequent inactivations).

\section{Lesions}

To induce permanent neuronal lesions while sparing fibers of passage, or axons passing through, excitotoxin microinfusions were made during surgery of either ibotenic acid $[15 \mu \mathrm{g}$ in $1 \mu \mathrm{L}$ of $0.1 \mathrm{~m}$

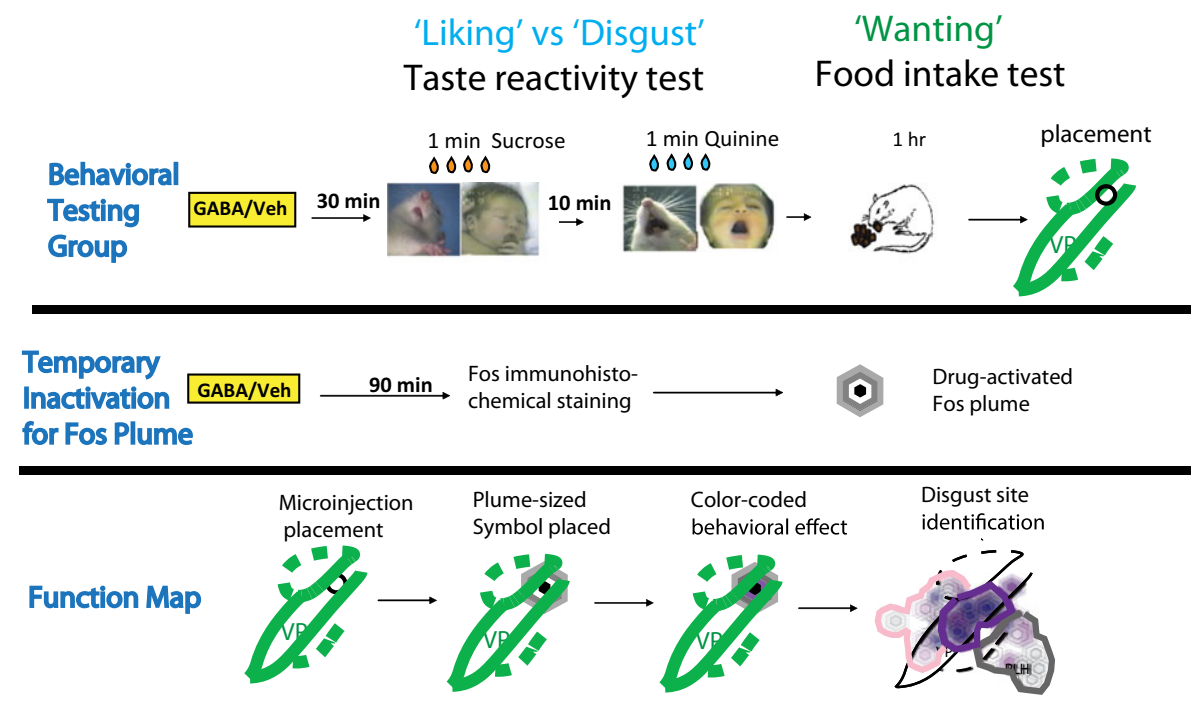

FIG. 1. Summary of the experimental design. Excitotoxin lesion and temporary GABAergic inactivation effects for the NAc and VP were tested in separate groups of rats (VP groups are shown). Also, additional groups were used to assess the maximal Fos plume size anatomically induced by GABAergic inactivation microinjections. Measurements of Fos plume radius and excitotoxin lesion radius were used to assign the respective symbol sizes in maps. Histologically identified sites where 'disgust' was produced by either lesions or inactivations were assessed on the basis of brains from behaviorally tested rats, and those sites were used to construct the respective maps of excessive 'disgust' reactions to sucrose. 
phosphate buffer (PB); in half of the lesion group; randomly assigned], quinolinic acid $(10 \mu \mathrm{g}$ in $1 \mu \mathrm{L}$ of $0.1 \mathrm{M} \mathrm{PB}$; the remaining half of the lesion group), or $\mathrm{PB}$ vehicle alone as the intact control condition ( $1 \mu \mathrm{L}$ of $\mathrm{PB}$ in control rats). Excitotoxin type was randomly assigned to rats, but functional effects turned out not to differ between ibotenic acid and quinolinic acid lesions (described below), which allowed the eventual combination of behavioral data. The excitotoxin solution was microinjected through a stainless-steel injector cannula (29-gauge) connected to PE-20 tubing and a syringe pump at a rate of $1 \mu \mathrm{L}$ for a period of $3 \mathrm{~min}$. Microinjectors were left in place for an additional $5 \mathrm{~min}$. After excitotoxin infusion, rats were maintained under halothane anesthesia for an additional $25 \mathrm{~min}$. Diazepam $(8 \mathrm{mg} / \mathrm{kg}$, intraperitoneal $)$ was given 5 and $35 \mathrm{~min}$ after excitotoxin infusion, to prevent seizures. In order to assess early effects of lesions, and therefore to make assessments that were as comparable as possible with pharmacological inactivations, behavioral tests began $24-48 \mathrm{~h}$ after lesions.

\section{Microinjection cannulae}

For rats in the pharmacological GABAergic inactivation groups, bilateral microinjection guide cannulae (23-gauge, stainless steel) were embedded in an acrylic headcap anchored with skull screws. Stainless-steel stylets (28-gauge) were always kept inserted, except during drug microinjections. Behavioral testing began 1 week after microinjection cannula implantation.

\section{Oral cannulae}

In the same operation, all rats were additionally implanted with intraoral cannulae (PE-100 tubing) for subsequent delivery of sucrose or quinine solutions into the mouth for taste reactivity tests (Grill \& Norgren, 1978a). Oral cannulae bilaterally entered the mouth lateral to the first maxillary molar, traveled beneath the zygomatic arch, and exited the dorsal head near the skull screws, where they were anchored to the headcap with dental cement. Oral cannulae did not disrupt normal eating or behavior.

After surgery, rats were given at least 7 days to recover from surgery before drug microinjection testing, and always had free access to moist cereal mash (Gerber's baby cereal mixed with water), food pellets and a water bottle in their home cages. During recovery after surgery, food intake was monitored by measuring the approximate amount of mash eaten each day, and by measuring body weights each day.

\section{Aphagia monitoring and intubation feeding}

Aphagia after lesions was defined as the failure to eat $>1 \mathrm{~g}$ of chow pellets or cereal mash per day. Hypophagia was defined as the failure to eat $>5 \mathrm{~g}$ per day (but $>1 \mathrm{~g}$ ). Rats showing aphagia or hypophagia, and that lost $>10 \mathrm{~g}$ of body weight after VP or LH lesions, were nourished and hydrated with supplementary intragastric intubations of a liquid diet, in amounts calibrated to body weight. The diet consisted of $6-12 \mathrm{~mL}$ of sweetened condensed milk mixed with an equal volume of water in three daily meals. The intubation volume was gradually increased to avoid excessive gastric distension. The first two meals consisted of $6 \mathrm{~mL}$, the next two meals consisted of $8 \mathrm{~mL}$, the next two meals consisted of $10 \mathrm{~mL}$, and meals consisted of $12 \mathrm{~mL}$ from then on. Each aphagic/hypophagic rate received one, two or three intubations per day, with the number of meals being individually adjusted daily to prevent weight loss.

\section{Induction of temporary inactivations}

Approximately $30 \mathrm{~min}$ prior to a behavioral test, temporary inactivations were induced by bilateral microinjections of a mixture of $\mathrm{GABA}_{\mathrm{A}}$ and $\mathrm{GABA}_{\mathrm{B}}$ agonists $[0.1 \mu \mathrm{g} / 0.2 \mu \mathrm{L}$ of muscimol, and $0.1 \mu \mathrm{g} / 0.2 \mu \mathrm{L}$ of baclofen, combined into $0.2 \mu \mathrm{L}$ of artificial cerebrospinal fluid (ACSF), per side], or of vehicle only as a within-subject control $(0.2 \mu \mathrm{L}$ of ACSF alone), immediately before behavioral tests (Fig. 1). Microinjections were made through a stainless-steel injector cannula (29-gauge) connected to PE-20 tubing and a syringe pump at a rate of $0.2 \mu \mathrm{L} / \mathrm{min}$, while the rat was gently hand-held. Microinjector tips were kept in place for an additional $1 \mathrm{~min}$ after the end of infusion, to avoid backflow. An additional group of control rats received only ACSF microinjections on all days, and never inactivations. For a particular rat designated for inactivation, the order of microinjections was always vehicle (ACSF) on the first day, and muscimol/baclofen on the second day (VP and surrounding regions, $n=35$; NAc, $n=15$ ). This vehicle/drug order was chosen because our initial pilot observations indicated that GABA microinjections in the VP often caused robust disgust reactions to tastes to persist for several days, and we did not wish to contaminate control vehicle tests with persistent aversion induced by previous GABAergic inactivations. The persistence may have been attributable to long-lasting neurobiological effects, or may have been partly associative, if the chamber paired with intense GABAergic disgust induced on a recent day contributed, as a conditioned stimulus, to a Pavlovian conditioned aversive response. However, our use of the separate group of vehicle/vehicle control rats that received vehicle on successive days allowed us to control for potential order effects. Repeated vehicle microinjections never appeared to induce changes in taste reactivity or food intake from one test day to the next. Two minutes after microinjections were completed, stylets were inserted back into the microinjection guide cannula, and rats were placed in the transparent taste reactivity chamber with intraoral fluid delivery tubing attached (described in 'Behavioral taste reactivity testing').

\section{Behavioral taste reactivity testing}

Prior to microinjections, rats were habituated in the taste reactivity chamber for four consecutive days for $30 \mathrm{~min}$ each, and received a mock injection of vehicle on the final habituation day.

For taste reactivity testing, on each test day, tubing (PE-50 connected to a PE-10 delivery nozzle) was attached to an intraoral cannula to deliver solutions to the mouth. The other end of the tubing was attached to a syringe pump, which infused solutions at a rate of $1 \mathrm{~mL} / \mathrm{min}$ during the 1-min test. Rats received sucrose solution (1\%, $1 \mathrm{~mL}$ in $1 \mathrm{~min}$ ). Orofacial positive hedonic and negative aversive taste reactivity responses were video-recorded via an angled mirror placed underneath the transparent floor. Most rats also received a quinine infusion $\left(3 \times 10^{-4} \mathrm{M}, 1\right.$-min duration $) \sim 10 \mathrm{~min}$ after their sucrose infusion (VP, $n=29$ rats). As the primary goal of this study was to assess the positive hedonic impact of sucrose and its replacement by disgust, sucrose was always infused before quinine, because hedonic liking responses to sucrose are generally more vulnerable to contamination from an immediate earlier experience, whereas aversive 'disliking' responses to quinine are more robust.

\section{Video scoring}

Video files of neutral and aversive response patterns elicited by tastes were stored offline for subsequent slow-motion analysis [frame-by-frame to 1/10th speed with OBSERVER software (Noldus, 
Inc., Wageningen, The Netherlands)]. The scorer was always blind to the drug/vehicle contents, lesion status and site placement of the rat during scoring (Berridge, 2000). Positive hedonic responses were rhythmic tongue protrusions, lateral tongue protrusions, and paw licks. Aversive or disgust responses were gapes, headshakes, face washes, forelimb flails, and chin rubs. Neutral responses (which are less consistently linked to hedonic/aversive taste valuation) included grooming, passive dripping of solution out of the mouth, and rhythmic mouth movement. A time-bin scoring procedure was used to ensure that various taste reactivity components contributed comparably to the final affective hedonic/aversive totals, even when components had different relative frequencies (Berridge, 2000). For example, rhythmic mouth movements, passive dripping of solution, paw-licking and grooming typically occur in long bouts, and were thus scored in 5-s time bins (1-5 s equals one bout occurrence). Tongue protrusions, which occur in shorter bouts, were scored in 2$\mathrm{s}$ time bins (0.2-2 s equals one bout occurrence). Other taste reactivity components (lateral tongue protrusions, gapes, forelimb flails, headshakes, and chin rubs) typically occur as discrete events, and were thus scored as single occurrences each time that they occurred (e.g. one gape equals one score). Finally, individual totals were calculated for hedonic vs. aversive categories by adding all response scores within an affective category for each rat. This total score was the sum of scores of all positive hedonic reactions: lateral tongue protrusions, rhythmic tongue protrusions, and paw licks. Similarly, an aversive 'disgust' score was the total sum of occurrences of gapes, headshakes, face washes, forelimb flails, and chin rubs.

\section{Food intake test}

A 1-h food intake test was performed after each taste reactivity test in order to quantify voluntary food consumption (Fig. 1). Rats were placed in a clean cage with bedding, chow pellets, palatable cereal mash, and a water bottle, all freely available for $1 \mathrm{~h}$. Afterwards, the remaining amounts of water, cereal mash and chow pellets were re-weighed and subtracted from the initial weights to compute the amount consumed. During the test, rats were also videotaped for subsequent offline scoring of eating, locomotion and other behaviors that occurred spontaneously during the 1 -h period.

\section{Histology and lesion/inactivation mapping}

To measure excitotoxin lesions, neuron loss was quantified and mapped with a technique for lesion mapping in which neurons at specified locations surrounding the lesion center are counted (Cromwell \& Berridge, 1993, 1994, 1996), modified from fractionator techniques (Gundersen et al., 1988; Gundersen, 2002). To measure temporary neuronal inactivation induced by combined $\mathrm{GABA}_{\mathrm{A}}$ and $\mathrm{GABA}_{\mathrm{B}}$ agonist microinjections, suppression of Fos protein expression surrounding the microinjector tip was quantified and mapped with a related Fos plume technique in which neurons expressing Fos at specified sites surrounding the microinjection center are counted (Peciña \& Berridge, 2005; Smith \& Berridge, 2005; Richard \& Berridge, 2011).

All rats received an overdose of sodium pentobarbital $(0.2 \mathrm{~g} / \mathrm{kg})$ prior to being transcardially perfused. Brains from rats that had been behaviorally tested were extracted and post-fixed with $10 \%$ formalin in $0.1 \mathrm{M} \mathrm{PB}$, and then transferred to $30 \%$ sucrose in $0.1 \mathrm{M} \mathrm{PB}$, sectioned with a freezing microtome into $60-\mu \mathrm{m}$ sections, and stained with cresyl violet. The locations of microinjection cannula tips were identified microscopically, and mapped onto a brain atlas for use in subsequent function mapping (Paxinos \& Watson, 2008).

\section{Mapping excitotoxin lesions via neuronal loss}

Baseline control values for neuronal density were first mapped in VP and NAc regions in normal rat brains at six levels along the AP axis (AP $0.3-0 \mathrm{~mm}$; AP 0 to $-0.3 \mathrm{~mm}$; AP -0.3 to $-0.65 \mathrm{~mm}$; AP -0.65 to $-1 \mathrm{~mm}$; AP -1 to $-1.6 \mathrm{~mm}$; AP after $-1.6 \mathrm{~mm}$ relative to bregma). Each AP slice section was divided into five to seven targeted regions that included the VP, and adjacent subareas of the LH, extended amygdala, and globus pallidus (GP) (Cromwell \& Berridge, 1993, 1994). Neuronal density was counted in contiguous sampling boxes $(125 \times 125 \mu \mathrm{m})$ at points on five axes emanating away from the center of excitotoxin injection (or of vehicle injection in control brains; Fig. 2). For lesions, the percentage neuronal death at each point was calculated relative to the baseline count at the same point in control brains. Excitotoxin lesion blocks were deemed to have 'intense neuronal loss' ( $>80 \%$ death) if $<20 \%$ of the normal number of neurons remained in that block (as compared with baseline norms for the same site obtained in control brains). 'Moderate neuronal loss' was defined as 20-50\% of neurons surviving, and 'mild neuronal loss' was defined as $>50 \%$ of neurons surviving.

\section{Fos plume mapping}

A separate group of rats received only one microinjection of GABA agonists or of vehicle $90 \mathrm{~min}$ prior to perfusion, and were processed for Fos plume mapping as previously described (Peciña \& Berridge, 2005; Smith \& Berridge, 2005; Richard \& Berridge, 2011). The use of a separate group for Fos plume mapping avoids distortion by the plume shrinkage that is gradually induced over a series of microinjections, and gives a more accurate measure of the maximal spread of local drug impact (Richard \& Berridge, 2011; Castro \& Berridge, 2014). Brain slices were processed for Fos-like immunoreactivity with normal donkey serum, goat anti-c-Fos (Santa Cruz Biotechnology), and donkey anti-goat Alexa Fluor 488 (Invitrogen). To visualize and quantify drug-induced Fos activities, Fos-labeled cells on the tissue surface were visualized with $\times 5$ to $\times 40$ magnification under a microscope followed by image processing (Fig. 2). Sampling blocks $(50 \times 50 \mu \mathrm{m})$ were placed along seven radial arms emanating from the center of the microinjection site $\left(45^{\circ}, 90^{\circ}, 135^{\circ}\right.$, $180^{\circ}, 225^{\circ}, 270^{\circ}$, and $315^{\circ}$ ) at $50-\mu \mathrm{m}$ intervals (Richard \& Berridge, 2011).

\section{Statistical analyses}

All behavioral analyses were two-tailed, and $\alpha$ was always set at $P<0.05$. Paired-sample $t$-tests or one-way ANovas with Bonferroni post hoc tests were used to test microinjection drug/vehicle effects, and between-subjects ANOVAs were used to compare lesion effects and anatomical site effects. For significant differences in behavioral taste reactivity scores, Cohen's $d$-statistic was used to calculate effect sizes.

\section{Results}

\section{Overview}

Our results suggest that the posterior half of the VP, which contains its previously identified hedonic hotspot, is also uniquely necessary for normal sucrose 'liking'. We found that either localized lesions or temporary inactivations in the posterior VP produced excessive disgust reactions to sweetness. In contrast, for the rostral half of the 


\section{Lesion mapping}

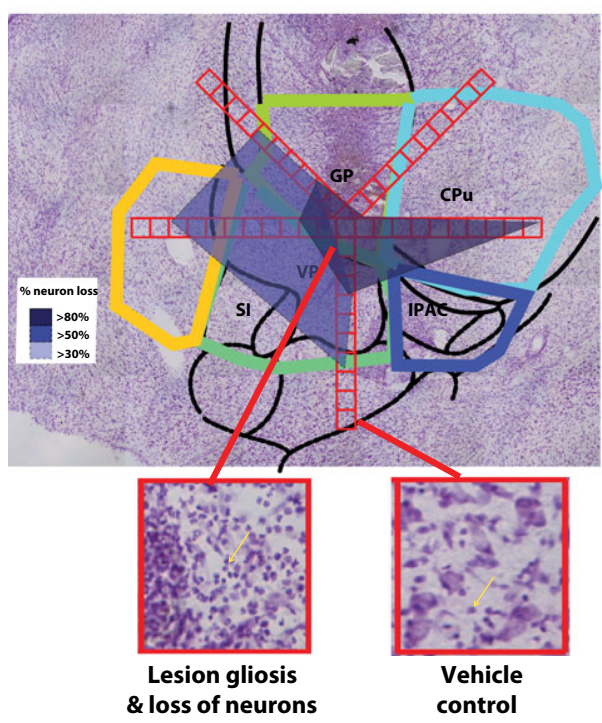

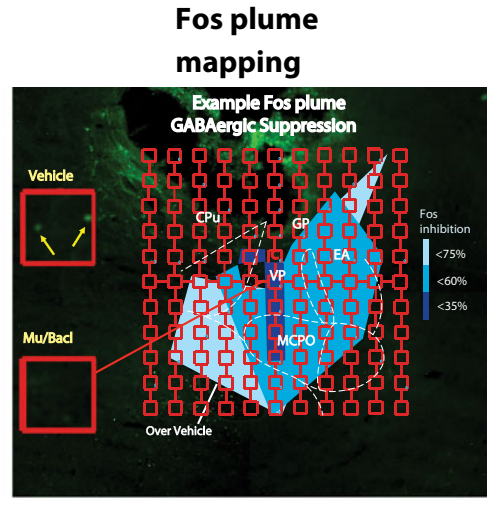

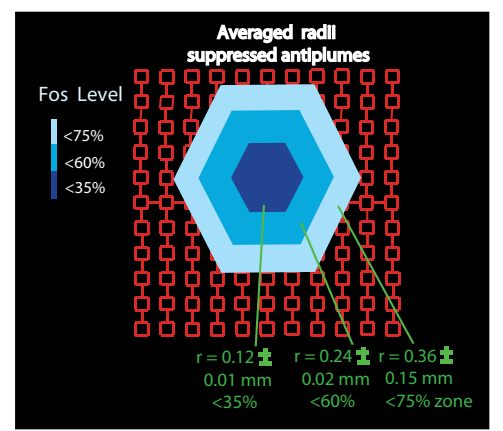

FIG. 2. Lesion and Fos plume measurement. Examples of how lesions and Fos plumes were measured, and sizes were integrated with site data from behaviorally tested rats to create function maps for disgust induction. Left: excitotoxin lesion map. Neurons were counted in $125 \times 125-\mu \mathrm{m}$ blocks on five sampling arms (red) extending from the excitotoxin injection center, and compared with same location baseline counts in control tissue that received only vehicle injection during surgery (Cromwell \& Berridge, 1993, 1994). The example photograph at the bottom left shows a sampling box of the lesion, showing gliosis (yellow arrow) and loss of larger neurons, and a photograph of a box from healthy control brain containing neurons ( $\times 40$ magnification). Colored areas in the coronal slice above indicate zones of $80 \%$ neuronal loss (dark blue), 50\% neuronal loss (sky blue) and 30\% neuronal loss (light blue) as compared with healthy tissue at the same locations. The right side shows, at the top, an example of Fos plume surrounding the tip of a microinjection of GABA agonist mixture $(0.1 \mu \mathrm{g}$ of muscimol; $0.1 \mu \mathrm{g}$ of baclofen). Sampling was performed in $50 \times 50-\mu \mathrm{m}$ blocks to count Fos-expressing neurons. The vehicle inset (Veh) shows a baseline example of moderate Fos expression in a block after ACSF microinjection ( $\times 10$ magnification; green dots are Fos neurons). The mu/bacl inset shows an example of suppressed Fos expression (i.e. antiplume) in an equivalent block after GABAergic microinjection of muscimol and baclofen. The bottom shows the average radius of Fos antiplumes produced by muscimol/baclofen microinjections, with three zones for inhibition intensity, which were used to assign the size of symbols in 'disgust' maps. CPu, caudate putamen; MCPO, magnocellular preoptic nucleus; SI, substantia innominata.

NAc shell, although it also contains a hedonic hotspot for opioid and related enhancements of positive 'liking' reactions, neither lesions nor inactivations produced disgust. Instead, only NAc sites in the posterior half of the medial shell produced intense 'disgust' (not the anterior half), and only after temporary inactivations (but not after lesions). Finally neither lesions nor inactivation sites anywhere in basal forebrain sites, such as the LH and extended amygdala, induced excessive 'disgust' reactions to sucrose, unless the posterior VP was also affected.

\section{Disgust after excitotoxin lesions}

\section{Excitotoxin lesion maps}

Excitotoxin microinjections produced roughly concentric spheres (total diameter, $1.6 \mathrm{~mm}$ ) of neuronal death and elevated gliosis: an inner sphere of severe neuronal loss and gliosis with a radius of $0.43 \pm 0.04 \mathrm{~mm}$, surrounded by a middle sphere of moderate neuronal loss with a radius of $0.733 \pm 0.041 \mathrm{~mm}$, surrounded by an outer sphere of mild neuronal loss with a radius of $0.82 \pm 0.03 \mathrm{~mm}$ ( $n=57$; Fig. 2). The zone of severe neuronal loss was defined as containing only $20 \%$ of the normal number of neurons counted at equivalent locations in normal control brains (i.e. $80 \%$ neuronal loss). The zone of moderate neuronal loss contained $30-50 \%$ of the normal number of neurons (i.e. 50-70\% neuronal loss). The zone of mild neuronal loss contained $50-90 \%$ of the normal number of neurons (i.e. 10-50\% neuronal loss) (Fig. 2). Ibotenic acid lesions and quinolinic acid lesions did not differ detectably from each other in either radius or intensity of neuronal loss in the NAc or VP, and nor did the two brain structures vary systematically in their lesion sizes. As described below, the evidence indicated that a damage threshold of approximately $65-80 \%$ neuronal loss was required to release excessive 'disgust' reactions at caudal VP sites; the only sites at which any lesion ever did.

\section{NAc hotspot lesions: no release of sensory 'disgust'}

Excitotoxin lesions in the NAc, whether in the rostral half or the caudal half of the medial shell, completely failed to cause detectable elevation of 'disgust' gapes, headshakes, forelimb flails or chin rubs in response to the taste of oral sucrose infusions (Fig. 3), or even to reduce the number of positive hedonic reactions elicited by sucrose $(P=0.78)$. Not even the most intense rostral NAc shell lesions, which destroyed $80 \%$ of neurons in the rostrodorsal quadrant of the medial shell, which contains the previously identified NAc hedonic hotspot, suppressed positive hedonic reactions to sweetness or produced gapes (Fig. 3). The taste of quinine remained able to elicit gapes and other 'disgust' reactions, but only at levels that remained comparable to those of vehicle control rats $(P=0.36)$. Similarly, food and water intake were not altered by NAc lesions. 


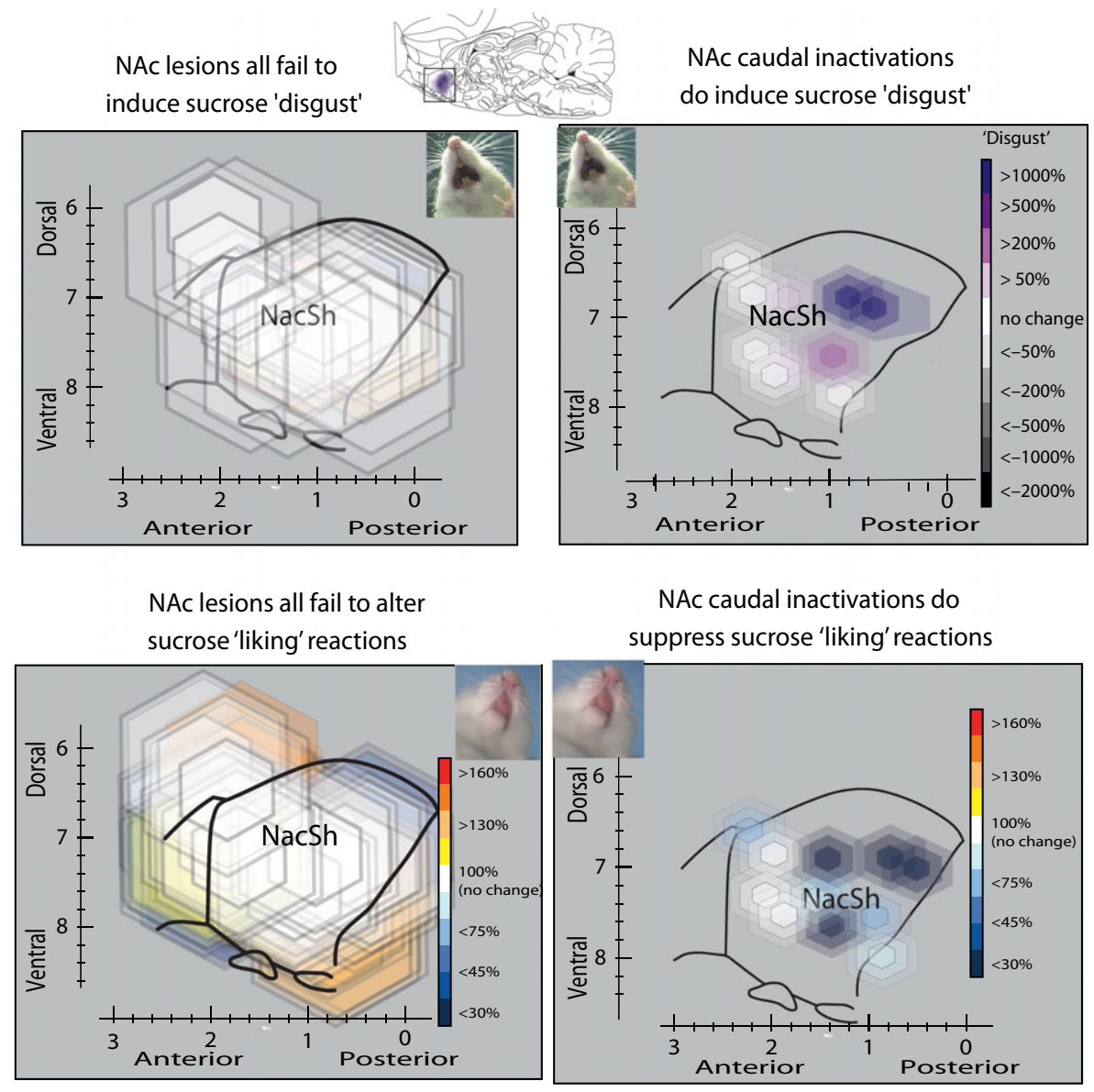

FIG. 3. Lesions of the NAc fail to alter hedonic impact, although caudal inactivations in the medial shell induce 'disgust'. NAc excitotoxin lesions had no effect on positive 'liking' reactions to sucrose (rhythmic tongue protrusions, lateral tongue protrusions, and paw licks), and did not induce 'disgust' reactions (gapes, headshakes, etc.), at any location in the medial shell. However, temporary inactivations by GABAergic microinjections in the caudal half of the medial shell did suppress 'liking' reactions and induce 'disgust' reactions to sucrose. The maps show sagittal views to display the entire NAc medial shell. Map symbols are colorcoded to show changes in positive vs. negative affective reactions induced at a site. NacSh, nucleus accumbens shell.

\section{VP hotspot lesions induce excessive disgust reactions}

The posterior half of the VP proved to be the chief site where excitotoxin lesions could produce intense disgust (Fig. 4). Here, lesions causing loss of $80 \%$ of neurons in the posterior VP zone essentially eliminated all positive hedonic reactions normally elicited by sucrose, which were replaced with negative 'disgust' gapes, etc. in numbers $>400 \%$ greater than in normal control rats $\left(F_{1,60}=4.29\right.$, $P<0.05, d=0.72)$. These effects were visible within $24-48 \mathrm{~h}$ after excitotoxin surgery, and persisted for several days to weeks. The intensity threshold of neuronal loss in the posterior VP needed to produce excessive 'disgust' appeared to be approximately $65-80 \%$ (severe neuronal loss: $<30 \%$ neurons remaining; Fig. 4). Rats with 65-70\% neuronal loss in the posterior VP showed a few 'disgust' reactions to sucrose, and the number of 'disgust' reactions appeared to increase further for lesions that produced neuronal loss reaching $80 \%$ (Fig. 4). As a group, rats that showed 'disgust' reactions to sucrose had an average of $74 \pm 1 \%$ neuronal loss in their lesion centers (i.e. $<26 \%$ of neurons remaining). The threshold for 'disgust' induction appeared to be similar to an earlier $>70 \%$ threshold found by a previous study of VP lesions (Cromwell \& Berridge, 1993). In contrast to sucrose reactions, no lesions (even in the posterior VP) altered 'disgust' reactions to the bitter quinine taste, which were already at high levels in control rats (gapes, headshakes, forelimb flails, and chin rubs). This may indicate that the high levels of quinine 'disgust' were already near a response ceiling even for control rats, and could not be increased further by the lesions used here. All rats that showed 'disgust' gapes, chin rubs, headshakes and forelimb flails in response to sucrose were also completely aphagic and adipsic at the same time (Fig. 5), neither eating nor drinking. Aphagia continued for at least 6 days in all rats with the most intense lesions in the VP or LH, and for $>10$ days in several rats, before food intake gradually began to recover. Aphagic rats were therefore maintained during this period with three intragastric intubations of liquid diet each day, beginning at $6 \mathrm{~mL}$ of milk diet and increasing gradually to $12 \mathrm{~mL}$. The intragastric intubations by themselves did not induce disgust in aphagic rats, as indicated, for example, by the failure to produce 'disgust' in aphagic LH lesion rats, anterior VP lesion rats or extended amygdala lesion rats that lacked VP damage. However, this does not rule out the possibility that pathological disgust might be capable of modulation by hunger/satiety states in future studies. For example, starvation has been reported to reduce lesioninduced 'disgust' (Fluharty \& Grill, 1981), and intubation to augment LH stimulation induced 'disgust' in previous studies (Hoebel \& Thompson, 1969), but we did not manipulate appetite states here.

In contrast, several rats that had less intense lesion damage, below the $65 \%$ neuronal loss threshold, in the same posterior hotspot region of the VP (average neuronal loss of $53 \%$, or $>47 \%$ of neurons remaining) never showed 'disgust' reactions to sucrose (Fig. 4), although several of these rats were similarly aphagic and adipsic, and 


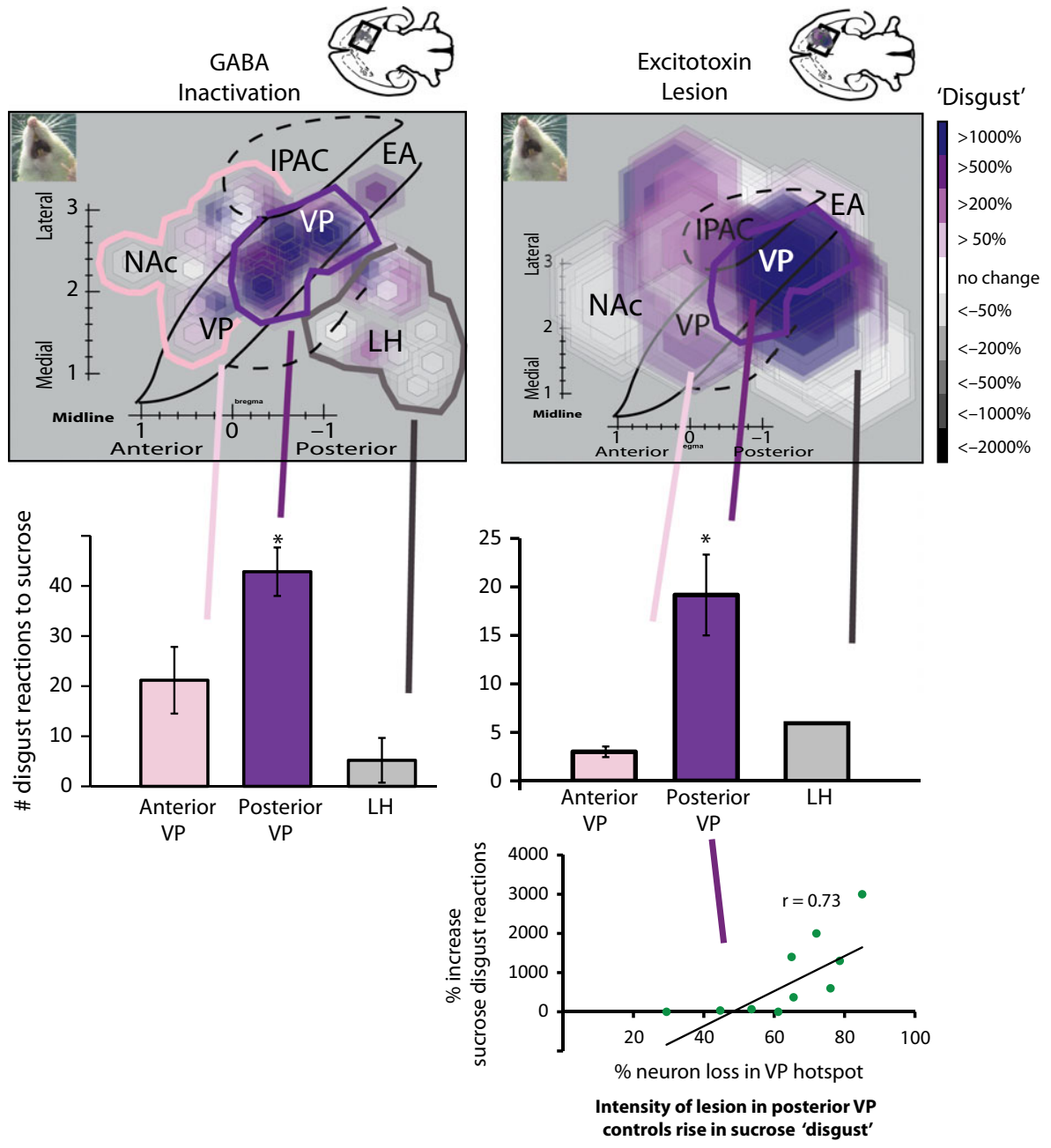

FIG. 4. Induction of disgust in the VP. Maps of 'disgust' reactions to sucrose after either temporary inactivations by GABAergic microinjections (left) or excitotoxin lesions (right) in the VP and nearby structures. Maps show a horizontal view ( $-8.4 \mathrm{~mm}$ below the skull surface) to display the entire VP. The small disgustinduction site in the posterior VP is seen most clearly in the map of GABAergic inactivations, oswing to the smaller radius of microinjection symbols. Larger lesion symbols create a more diffuse zone of 'disgust' induction, especially because some lesions centered in the LH or in the extended amygdala still impinged on the caudal VP. Bar graphs show the absolute numbers of disgust reactions to sucrose induced by inactivation/lesion sites centered in the posterior VP (disgust site), LH, or anterior VP, as compared with baseline levels measured in control rats (for lesions) or in the same rats after control vehicle microinjections (for inactivations). The scatterplot and regression analysis at the bottom shows the correlation between lesion intensity (\% neurons destroyed) and 'disgust' produced by excitotoxin lesions in the posterior VP. EA, extended amygdala; IPAC, interstitial nucleus of the posterior limb of the anterior commissure. ${ }^{*} P<0.01$.

received similar gastric intubations to maintain body weight. Therefore, when constructing lesion maps for causation of 'disgust' reactions to sucrose, we specifically mapped zones containing $70-80 \%$ neuronal loss from rats that showed disgust reactions to sucrose. This was performed according to the premise that a shared zone of 70$80 \%$ neuronal loss, which was common to all rats showing excessive disgust reactions, would best capture the critical brain region where neuronal loss induces abnormal sensory 'disgust' reactions to sucrose.

\section{Disgust-release site in the posterior VP}

The posterior VP 'disgust' site was assessed by functional mapping to have a radius of $\sim 0.6 \mathrm{~mm}$, centered at approximately AP $-1.3 \mathrm{~mm}$ posterior to bregma, $\pm 2.4 \mathrm{~mm}$ lateral from the midline, and DV $-8.2 \mathrm{~mm}$ ventral to the skull surface (Figs 4 and 6). In terms of anatomical boundaries, the disgust lesion zone extended posteriorly to the caudal border of the posterior VP, at an AP level adjacent to the sublenticular extended amygdala (SLEA) (AP -1.4 to $-1.8 \mathrm{~mm}$ ). Anteriorly, the disgust-induction site extended approximately to the middle of the VP (AP +0.3 to $0.0 \mathrm{~mm}$ ), but did not appear to include the anterior half of the VP (i.e. did not extend $+0.3 \mathrm{~mm}$ rostral to bregma).

Rats with $80 \%$ neuronal loss in this posterior VP 'disgust' lesion zone showed far more disgust reactions to sucrose than rats with lesions sited at other locations outside the posterior VP, even when those other locations had comparably intense $80 \%$ neuronal loss $\left(F_{1,60}=4.16, P<0.05, d=-0.623\right)$. These outside lesion sites included severe lesions in either anterior VP, LH or extended amygdala sites near the VP (as well as in the NAc shell). None of these other non-VP lesions produced intense 'disgust' reactions to sucrose, even though the damaged sites contained only $20 \%$ of the normal neuronal density for those locations.

Suppression of positive 'liking' reactions to sucrose (without necessarily being accompanied by negative 'disgust' induction) was produced by a somewhat wider range of sites in and outside the VP (Fig. 5). 'Liking' suppression was produced by lesions throughout the VP, and by lesions in other adjacent structures, including the LH, SLEA, or substantia innominata, and extending anteriorly to the 
VP Suppression of Sucrose 'Liking' Reactions

activation
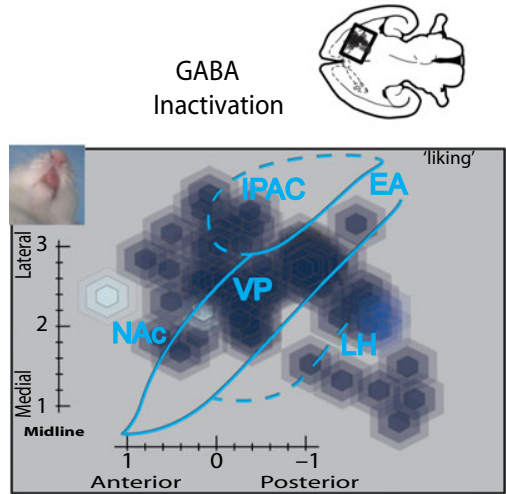

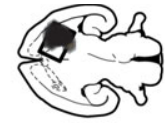
Lesion

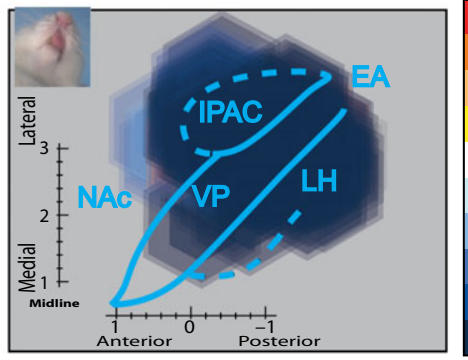

Sucrose 'liking'

Reactions

$>160 \%$

$>145 \%$

$>130 \%$

$>115 \%$

$100 \%$

(no change)

$<95 \%$

$<75 \%$

$<60 \%$

$<45 \%$

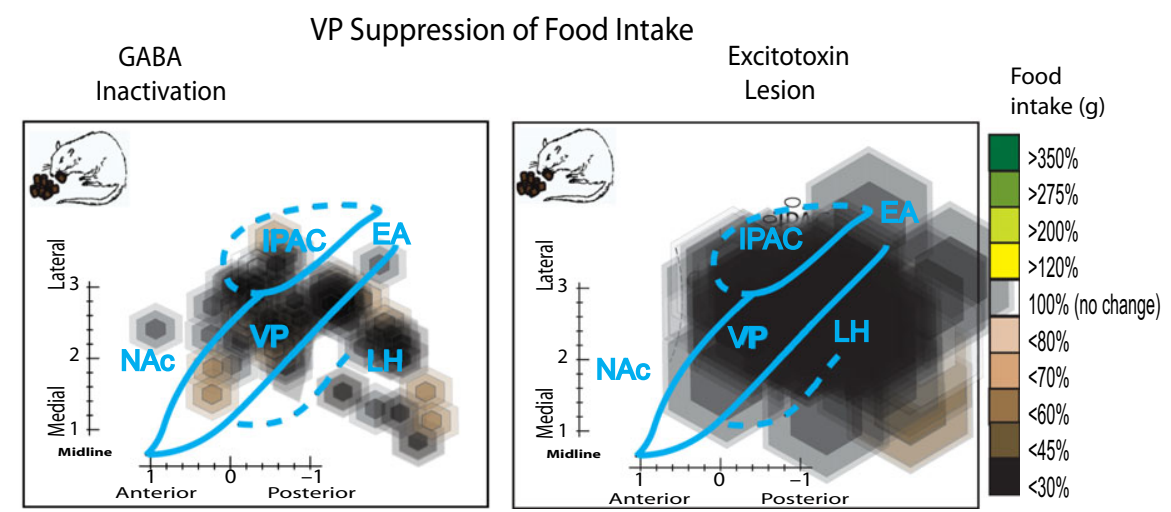

FIG. 5. Suppression of positive 'liking' reactions and of food intake in the VP. The top maps show changes in positive hedonic reactions to sucrose induced by temporary inactivations or lesions in the VP and in nearby structures. Suppression of 'liking' reactions is distributed more widely across sites in the VP, LH and substantia innominata (SI) than 'disgust' induction (this is especially visible for inactivations, which had smaller diameters than lesions), although it was still often most intense at sites in the posterior VP. The bottom maps show reduction in food intake, which was also induced widely at sites in the VP, LH, and SI. EA, extended amygdala; IPAC, interstitial nucleus of the posterior limb of the anterior commissure.

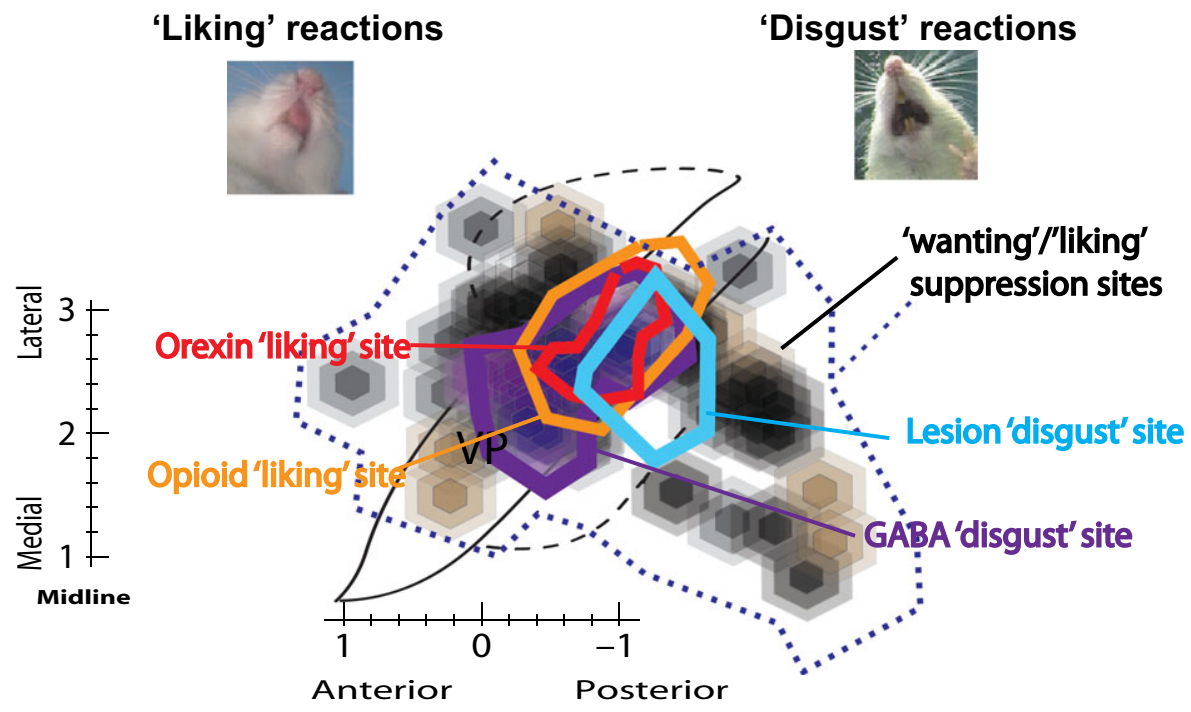

FIG. 6. Summary comparison of the VP 'disgust' site with the earlier opioid/orexin hedonic hotspot. The horizontal map shows the maximal 'disgust' release sites found here for temporary GABA inactivations (purple) and for excitotoxin lesions (blue), in comparison with previous maps reported for the hedonic hotspot in the posterior VP for $\mu$-opioid enhancement of sucrose liking reactions (orange) (Smith \& Berridge, 2005), and for orexin enhancement of sucrose 'liking' reactions (red) (Ho \& Berridge, 2013). Additional black and brown symbols show suppression of motivation for food intake, which extended well beyond the posterior VP hotspot for pharmacological 'liking' enhancement or dysfunction-induced 'disgust'. 
caudal NAc medial shell and dorsally to the ventral neostriatum. Lesions centered in all of these structures appeared to induce a reduction of the number of positive 'liking' reactions elicited by sucrose to approximately one-tenth to one-third of normal levels $\left(F_{1,106}=44.37, P<0.01, d=1.12\right.$; Fig. 5). However, as a caveat, a number of lesions centered at these sites appeared to have wider penumbras of mild neuronal loss that also penetrated near or into the posterior VP. Thus, it is possible that mild VP hotspot damage contributed to hedonic suppression, even if the damage was not intense enough loss to induce disgust.

\section{Contrast of disgust with aphagia}

Aphagia and adipsia (without excessive 'disgust') was induced by many basal forebrain lesions in a considerably larger region than the posterior VP, extending to at least $3-5 \mathrm{~mm}^{3}$ in volume (Fig. 5). Aphagia and adipsia followed lesions in the rostral VP as well as in the caudal VP, and also followed all lesions in the LH, where 70$80 \%$ neuronal loss was produced: food intake was near-zero, and far below that of intact control rats $\left(F_{2,177}=22.91, P<0.01, d=1.07\right)$. Aphagia and adipsia typically lasted from several days to a week. In contrast, NAc lesions, either in the rostral half or the caudal half of the medial shell, never produced aphagia or adipsia (or 'disgust'). Even for $80 \%$ lesions centered in the NAc hotspot of the rostrodorsal quadrant of the medial shell, no increase in disgust reactions or decrease in positive hedonic reactions was produced, and nor was there any detectable impairment of intake ( $n=19$, not significant).

\section{Temporary inactivations by muscimol/baclofen microinjections}

\section{Fos inhibitory plume maps surrounding GABAergic microinjection} tips

To map the brain sites responsible for the behavioral effects of temporary pharmacological inhibition, local changes in Fos protein expression (Fos plumes) were measured around the sites of microinjection of GABA agonists. The first inhibitory microinjections of the muscimol/baclofen mixture in the Fos group of rats produced suppression of local Fos expression in neurons surrounding the microinjection site, detectable as inhibitory Fos 'antiplumes', as compared with levels at similar VP sites in control rats that received no microinjection. Inhibitory Fos antiplumes were $\sim 0.35 \mathrm{~mm}$ in total radius, which is similar what was found in a previous muscimol microinjection study (Faure et al., 2010), and contained an inner sphere of heaviest $(>65 \%)$ Fos suppression (i.e. only $<35 \%$ of normal levels of Fos in the VP) of radius $0.12 \pm 0.01 \mathrm{~mm}$, surrounded by a middle zone of moderate (40-65\%) suppression (i.e. $35-60 \%$ of normal levels) of radius $0.24 \pm 0.02 \mathrm{~mm}$, surrounded by an outer sphere of mild (25-40\%) suppression (i.e. 60-75\% normal levels) of radius $0.35 \pm 0.15 \mathrm{~mm}$ (Fig. 2). The size of symbols in microinjection causation maps for excessive 'disgust' was therefore assigned to be $0.35 \mathrm{~mm}$ in radius to represent the maximal observed spread (equal to the outer inhibitory plume). All data in plume maps other than plume radius reflect functional consequences of muscimol/baclofen microinjections measured in behaviorally tested rats, and are assigned to the microinjection site to show behavioral causation (location, symbol color, and bar graphs).

\section{NAc inactivation: posterior aversion, but not rostral hotspot}

In the NAc, only sites located in the caudal two-thirds of the medial shell produced excessive 'disgust' reactions to sucrose after
GABAergic microinjections as compared with vehicle control microinjections in the same rats $\left(F_{1,8}=9.232, P=0.016, d=-1.28\right.$; Fig. 3). In contrast, microinjections of muscimol/baclofen into the rostral third of the medial shell (including the rostrodorsal quadrant of the medial shell, which contains the previously identified hedonic hotspot) failed either to release 'disgust' reactions to sweetness or to significantly reduce the number of positive hedonic reactions to sucrose (Fig. 3). This anatomical pattern followed a similar rostrocaudal gradient for 'disgust' induction as previously reported for pure muscimol microinjections in the medial shell (Reynolds \& Berridge, 2001, 2002; Faure et al., 2010; Richard et al., 2013b). The posterior zone of the NAc shell, where temporary GABA hyperpolarization caused excessive 'disgust' reactions to sucrose, stretched approximately from AP levels $+1.2 \mathrm{~mm}$ to $+0.6 \mathrm{~mm}$ relative to bregma. Food consumption was similarly blocked after posterior NAc GABAergic microinjections in the caudal half of the medial shell at sites that induced 'disgust' $\left(F_{1,8}=9.595, P=0.01\right.$, $d=-1.08$ ) (Reynolds \& Berridge, 2002). In contrast, anterior NAc microinjections of muscimol/baclofen produced, if anything, a trend towards increased food intake, although this was not statistically significant in the current study. Many previous studies have reported robust increases in food intake after muscimol microinjections in the anterior half of the NAc medial shell, including in our laboratory (Stratford \& Kelley, 1997, 1999; Basso \& Kelley, 1999; Reynolds \& Berridge, 2002; Stratford, 2005; Faure et al., 2010; Wirtshafter \& Stratford, 2010; Stratford \& Wirtshafter, 2012; Richard et al., 2013b). Possibly, our failure to observe significant increases in feeding after microinjections in the anterior half of the medial shell was attributable to the temporal interpolation of taste reactivity testing between microinjection and the intake test, or is a complication arising from the addition of baclofen to muscimol (most previous studies used one alone, usually muscimol), or is due to a relatively low number of microinjection sites located in the rostral shell.

\section{Inactivation of the posterior VP hotspot releases disgust}

Microinjections of GABA agonists in the posterior region of the VP caused subsequent exposure to sucrose to elicit intense 'disgust' reactions that reached $>200$-fold of normal baseline levels assessed in the same rats after vehicle microinjection $\left(F_{1,62}=32.141\right.$, $P=0.001, d=-2.56$; Fig. 4). The anatomical boundaries of the 'disgust site' in the posterior VP extended anteriorly to the middle $\mathrm{VP}$ (AP -0.1 to $-0.6 \mathrm{~mm}$ relative to bregma), and posteriorly to the caudal edge of the VP bordering the SLEA (AP $-1.5 \mathrm{~mm}$ relative to bregma) (Figs 4 and 6), and the total volume of the site was estimated to be $\sim 1.0 \mathrm{~mm}^{3}$ (which constitutes approximately onethird of the total volume of the entire VP).

Sites within the posterior VP produced more intense increases in 'disgust' reactions after muscimol/baclofen microinjections than sites in the anterior VP, or than sites in nearby outside structures, such as the LH and SLEA $\left(F_{2,30}=9.97, P<0.05, d=1.0\right)$. However, sites in the LH that were within $1 \mathrm{~mm}$ of the VP boundary did produce at least intermediate levels of 'disgust' reactions to sucrose, but no disgust reactions were produced by further sites in the LH, SLEA or ventral neostriatum that were $>1 \mathrm{~mm}$ away from the posterior VP (suggesting that some proximal LH 'disgust' impact may have been attributable to distant muscimol/baclofen diffusion reaching the VP slightly beyond our symbol radius, which was based on the measured suppression of Fos expression). Furthermore, many sites for GABAergic microinjections did suppress positive 'liking' reactions to sucrose even at other distant locations in the LH or SLEA, which were $>1 \mathrm{~mm}$ from the VP, although they still failed to generate any 
'disgust' reactions to sucrose (Fig. 2). Disgust reactions to quinine, which were already at high levels even after vehicle microinjections, were not further increased by muscimol/baclofen microinjections at any site (even in the posterior VP) $\left(F_{1,72}=1.038, P>0.05\right.$, $d=-0.2$ ). This lack of effect on quinine-evoked reactions was similar to what was found for the lesions above, again perhaps indicating a response ceiling for already-aversive bitterness. Finally, muscimol/baclofen at most sites in the LH and VP also suppressed or abolished food consumption in the free intake test that followed taste reactivity testing, as did most sites in the VP.

Comparison of inactivation site with lesion site in the VP. On explicit comparison of excitotoxin lesions with temporary pharmacological inactivations as ways of defining the posterior VP site for 'disgust' release, GABAergic microinjections produced twice the number of gapes and other disgust reactions to sucrose as excitotoxin lesions at the same site [degrees of freedom $=24, P=0.015$, $d=-1.429$; Fig. 4). However, GABAergic microinjections produced smaller radius impacts, and therefore tighter maps for the site of 'disgust' induction. Overall, the anatomical site centered similarly on the posterior VP for both lesions and inactivations, with the lesion site map appearing larger than the GABA-inactivation site map. The reason for the size difference between mapped disgust sites might be that a lesion intense enough to kill at least $80 \%$ of neurons in its center also tended to be large enough to produce substantial lesser damage at more distant sites (even if the damage to those distant sites did not substantially contribute to disgust). Given that the inactivation map gives the slightly smaller site, we conclude it to be the most precise depiction, and suggest that the GABAergic map most accurately reflects the true 'disgust'-induction site in the posterior VP. Finally, it is of interest to compare the VP disgustinduction site identified here with the previously identified VP hedonic hotspot where opioid/orexin microinjections in normal rats cause enhancements of positive 'liking' reactions to sucrose (Smith \& Berridge, 2005, 2007; Ho \& Berridge, 2013). As expected, when they are laid on top of each other, a map of the anatomical center and boundaries of the VP 'disgust' site for lesions or inactivations appears nearly identical to the map of the VP hedonic hotspot reported in those earlier 'liking' enhancement studies (Fig. 6).

\section{Discussion}

Our results indicate that, for excitotoxin lesions, only the posterior VP is able to produce intense 'disgust' reactions to sucrose after loss of $65-80 \%$ of neurons within the VP hotspot. High levels of 'disgust' reactions to sucrose were also produced by temporary inactivation of the posterior VP hotspot caused by microinjections of GABA agonists, which presumably hyperpolarized nearby neurons via GABA opening of membrane chloride ion gates. By comparison, for the NAc hedonic hotspot in the rostral medial shell, neither lesions nor inactivations caused 'disgust' reactions to sucrose. Instead, excessive disgust was produced only from the posterior two-thirds of the NAc medial shell, and only after temporary inactivations by muscimol/baclofen microinjections (and never after excitotoxin lesions, even in the posterior NAc shell). Finally, for other sites in structures such as the LH or extended amygdala, neither lesions nor inactivations ever caused 'disgust', even when they impaired food and water intake, as long as the posterior VP hotspot was spared (remaining outside the LH or extended amygdala excitotoxin lesion or GABAergic microinjection spread, as indicated by neuron counts or Fos plumes).

This pattern might be summarized by saying that the VP hotspot is uniquely needed for normal liking levels to be generated in the forebrain circuitry, leaving 'disgust' in its absence (as well as being a site able to neurochemically enhance 'liking' to higher levels than normal) (Smith \& Berridge, 2005, 2007; Ho \& Berridge, 2013). By comparison, the NAc shell segregates hedonic enhancement mechanisms into the rostral half of the medial shell, whereas excessive 'disgust' is predominantly produced more posteriorly by manipulations in the caudal half of the medial shell. Within the posterior NAc shell, the relatively phasic impairment of neuronal function induced by temporary GABAergic inactivation (i.e. minutes to hours after microinjection) was potent at releasing 'disgust'.

However, posterior NAc sites did not produce the more enduring chronic impairment induced by excitotoxin destruction of NAc neurons. The difference between GABAergic microinjections and lesions for the posterior NAc might reflect compensatory adjustments occurring in the remaining affective brain circuitry occurring over the first $24-48 \mathrm{~h}$ after an NAc lesion, which are not able to occur in the shorter period of a few minutes to an hour between the GABAergic microinjection and a taste reactivity test. The difference may also reflect an intensity difference in the impact of the two manipulations. That is, GABAergic microinjections more powerfully impact on function than lesions even at a single site: for example, GABAergic microinjections in the posterior VP produced approximately twice the number of 'disgust' reactions to sucrose as did excitotoxin lesions in the same VP site. Another reason why NAc lesions failed to produce 'disgust', but posterior VP lesions did, might be the opposite neuronal polarization mechanisms posited for the NAc and VP in reward functions, which arise from reciprocal GABAergic interconnections between the two structures (Kelley et al., 2005; Baldo \& Kelley, 2007; Carlezon \& Thomas, 2009). That is, NAc hyperpolarization or inhibition has been proposed to be a chief neuronal mechanism of reward (Roitman et al., 2005, 2010; Carlezon \& Thomas, 2009; Krause et al., 2010), whereas VP neuronal depolarization or excitation appears to be more directly linked to reward functions (Tindell et al., 2004, 2006; Carlezon \& Thomas, 2009; Root et al., 2010; Smith et al., 2011). In this framework, NAc may thus play a relatively permissive role in reward and incentive motivation, via disinhibiting targets, including the VP. In contrast, VP excitation may play a more direct role in generating reward functions. Loss of VP neurons might therefore more dramatically tilt the affective balance towards negative affects, including disgust. However, we note as a counterpoint to this explanation that NAc excitations (perhaps of different neuronal subpopulations) may also participate in reward (Ambroggi et al., 2011), and NAc pharmacological inhibitions in the caudal shell can clearly induce disgust, as seen here, suggesting that NAc inhibitions are not purely linked to reward.

Another potential basis for disgust, at least for taste disgust, is that the VP has more extensive reciprocal projections than the NAc with brainstem gustatory relays in rodents, such as the parabrachial nucleus of the pons (Norgren \& Leonard, 1973; Wu et al., 2012). It may also be relevant that VP neurons more directly synapse onto dopaminergic neurons in the ventral tegmental area, which might especially mediate appetitive motivation, whereas NAc projections synapse only onto non-dopaminergic neurons (Xia et al., 2011; Hjelmstad et al., 2013). However, as a caveat to this explanation, the GABAergic inhibitory nature of both projections does present a puzzle for how VP excitations could drive dopamine firing, unless additional other synapses or co-neurotransmitters are involved (Sesack \& Grace, 2010).

Whatever the neuronal mechanism for disgust production, it seems intriguing that reciprocal projections may connect the posterior half of the NAc medial shell (where 'disgust' is produced at 
least by GABAergic microinjections) to the posterior half of the VP (Groenewegen et al., 1993) (where 'disgust' is produced by both GABAergic microinjections and lesions), raising the possibility that the two disgust-inducing sites in the NAc and VP may be anatomically interconnected. The NAc core also projects to the posterior VP, whereas, by comparison, the rostral medial shell of the NAc may connect more predominantly with the anterior VP (Groenewegen et al., 1993; Thompson \& Swanson, 2010).

\section{VP hotspot: unique site for normal pleasure and liking enhancement}

The 'disgust'-releasing site in the posterior VP appeared to be essentially identical in anatomical boundaries to the VP hedonic hotspot previously identified for the enhancements of sensory pleasure via microinjections that deliver opioid or orexin neurochemical stimulation (Smith \& Berridge, 2005, 2007; Ho \& Berridge, 2013) (Fig. 6). That same VP hotspot also contains neurons in which firing increases code hedonic palatability of sweet, salty and bitter tastes, and the modulation of palatability via changes in natural appetite/ satiety states or brain manipulations (Tindell et al., 2004, 2005, 2006; Smith et al., 2011).

Our results also confirm previous reports that VP lesions or muscimol microinjections produce excessive 'disgust' reactions to sweet tastes (Cromwell \& Berridge, 1993; Shimura et al., 2006), whereas the same manipulations of the LH or extended amygdala do not (if the VP remains spared) (Cromwell \& Berridge, 1993). Our results additionally reveal that the VP subregion that is most responsible for 'disgust' appears to be limited to the posterior half of the VP. In contrast, only mere passive aphagia or hypophagia (without active disgust reactions to sucrose, although often with suppression of positive hedonic 'liking' reactions) was produced by damage in a larger, surrounding $5-\mathrm{mm}^{3}$ area, including the anterior VP, LH and SLEA (Schallert \& Whishaw, 1978). The large region for induction of aphagia and adipsia is also consistent with previous reports on diverse LH or GP lesions (Morgane, 1961; Teitelbaum \& Epstein, 1962; Schallert \& Whishaw, 1978; Cromwell \& Berridge, 1993, 1994).

Regarding differences in function between the anterior VP and the posterior VP, further support is provided by reports that temporary inactivation of the posterior VP in rats reduces reinstatement of cocaine reward pursuit primed by either cocaine administration or by aversive stress, whereas inactivation of the anterior VP more effectively reduces priming of cocaine pursuit by learned drug-predicting cues (McFarland \& Kalivas, 2001; McFarland et al., 2004; Mahler et al., 2014). Furthermore, opioid microinjections in the posterior VP increase the unconditioned consumption of food, enhance 'liking' orofacial reactions to sucrose hedonic impact, and increase instrumental responses to earn electrode self-stimulation in the LH (in addition to increasing 'liking' reactions to sucrose), whereas the same opioid microinjections in the anterior VP suppress eating and self-stimulation (in addition to suppressing sucrose liking) (Johnson et al., 1993; Smith \& Berridge, 2005). Conversely, opioid antagonist microinjection in the posterior VP blocks the hedonic alliesthesia or palatability enhancement normally produced by hunger or by NAc opioid stimulation (Smith \& Berridge, 2007; Wassum et al., 2009). Thus, the VP appears to have strong localization of function differences between the rostral and caudal subregions.

The neurobiological basis of why the posterior VP hotspot is more important than the anterior half of the VP to disgust induction remains unknown, but there are several special neurobiological features of the posterior VP that might be important to localization of hedonic/disgust function. For example, the posterior VP has been reported to have higher levels of enkephalin neurotransmitter expression than the anterior VP (accompanied by a lower density of presynaptic $\mu$-opioid receptors), and also a higher ratio of non-cholinergic neurons to cholinergic neurons (Maidment et al., 1989; Bengtson \& Osborne, 2000). There are also important connectivity differences between the posterior VP and the anterior VP, involving projections to the NAc, medial prefrontal cortex, insular cortex, and somatosensory cortex (Zahm \& Heimer, 1990; Groenewegen et al., 1993; Zahm et al., 1996, 2013).

\section{NAc: segregation of rostral pleasure enhancement and caudal disgust induction}

In contrast to the VP hotspot, our results indicate that, for the NAc, the rostrodorsal quadrant of the medial shell is not a site for disgust induction, despite containing another hotspot for hedonic enhancement by opioid or endocannabinoid stimulation (Peciña \& Berridge, 2005; Mahler et al., 2007; Smith \& Berridge, 2007; Smith et al., 2011; Castro \& Berridge, 2014). Neither permanent excitotoxin lesions nor temporary GABAergic inactivations in the anterior half of the NAc medial shell were able to increase 'disgust' reactions to sucrose, or even to suppress positive liking reactions to sucrose.

For the NAc, 'disgust' was induced only by GABAergic microinjections, and only at sites in the posterior two-thirds of the medial shell. This NAc caudal bias for temporary inactivation 'disgust' may also fit within a larger rostrocaudal affective keyboard pattern of anatomical organization of valence function previously found for the NAc shell. For example, GABAergic muscimol microinjections in the posterior medial shell also produce actively coping 'fear' (e.g. defensive anti-predator reactions such as directional treading/burying) and establish conditioned place avoidance, whereas rostral NAc shell sites produce appetitive increases in eating and food-seeking behavior and sometimes even 'liking' enhancements (Stratford \& Kelley, 1997; Reynolds \& Berridge, 2002; Faure et al., 2010; Wirtshafter \& Stratford, 2010; Richard et al., 2013b). Localization of function across different rostrocaudal subregions of the NAc medial shell might be viewed as simply extending the principle of anatomical heterogeneity for reward motivation that is already well recognized for the larger shell vs. the core components of the NAc (Meredith et al., 2008; Besson et al., 2010; Rocha \& Kalivas, 2010; Ambroggi et al., 2011; Cacciapaglia et al., 2012; Resendez et al., 2013).

\section{Disgust release in a historical context}

Over a century ago, the neurologist John Hughlings Jackson proposed that active behavioral symptoms caused by brain damage might be understood as 'release phenomena' (Hughlings Jackson, 1958). Jackson wrote: 'We must never speak of destructive lesions causing positive symptoms. It is erroneous, I submit to say that any sort of disease causes elaborate positive mental symptoms illusions, hallucinations, etc.' Instead, 'it causes a negative mental condition, the elaborate positive mental symptoms are permitted' (italics in original, p. 192, 1958; originally published 1879). By 'negative' mental condition, Jackson meant a loss of some particular function (e.g. loss of pleasure or liking reactions here), and by 'positive' symptom he meant any intense new and pathologically intense process (e.g. disgust). Applied here, Jackson's term 'positive mental symptom' would not refer to positive-valence 'liking', but rather to intense negative-valence 'disgust'. 
In this Jacksonian view, a VP lesion causes a release phenomenon: the sudden removal of inhibitory influences that are normally exerted over other circuitry, producing disinhibition and apparent excitation of the dramatic new symptoms. Arguably, this release phenomenon framework applies to the induction of intense sensory disgust by our posterior VP lesions/inactivations or by posterior NAc shell inactivations. This would mean that lesions of the VP did not quite 'cause' the excessive disgust. Instead, VP lesions removed either antagonistic opposition by 'liking' (via impairing a positive hedonic mechanism) and/or removed descending inhibitory control (via impairing the hierarchical modulation that normally suppresses disgust). In either case, the removal freed the remaining negativeaffect circuitry elsewhere to generate excessive disgust. A release interpretation is also consistent with observations that the excessive disgust reactions to sweetness released by lesions gradually fade over days to weeks, suggesting that hyper-reactivity of the remaining disgust circuitry eventually declines, resulting in restoration of the affective balance (Teitelbaum \& Epstein, 1962; Cromwell \& Berridge, 1993). The identity of the remaining negative-valenced circuitry that generates disgust in the absence of the posterior VP has yet to be identified, but it plausibly involves the anterior VP and regions of the hypothalamus, as well as the striatum, amygdala, and insula cortex (Calder et al., 2001, 2007; Heining et al., 2003; Murphy et al., 2003; Sambataro et al., 2006; Hayes et al., 2007; Johnson et al., 2007; Mataix-Cols et al., 2008; Chapman \& Anderson, 2012; Klucken et al., 2012).

Historically, only a few subcortical forebrain ablations or lesions have produced intense negative emotional reactions in the forms of excessive disgust, fear, or rage. In transection studies, disgust reactions to sweetness and irritable aggressive reactions to handling were reported by Grill and Norgren in so-called 'thalamic rats', which possessed a thalamus and brainstem, but had suction ablation of all telencephalic structures: the basal ganglia (including the neostriatum, the NAc, and probably the GP and VP), septum, hippocampus, and neocortex (Grill \& Norgren, 1978a). Similarly, earlier transection studies of cats by Bard and Cannon found intense negative affective reactions in the form of 'thalamic rage' after ablations of telencephalic structures either above the thalamus or above the hypothalamus (and including the thalamus) (Cannon, 1927; Bard, 1934). Conceivably, all of those ablations may have eliminated the posterior VP if they succeeded in destroying all structures rostral to the anterior edge of the hypothalamus and thalamus. In contrast to the intense negative affect produced by such thalamic/hypothalamic ablations, neither rage nor disgust is produced when transections are made more anterior to the thalamic level, such as removing the neocortex alone but leaving intact the striato-pallidal circuitry and other telencephalic subcortical structures (Sorenson \& Ellison, 1970; Warren et al., 1972; Vanderwolf et al., 1978; Wirsig \& Grill, 1982). Similarly, no excessive rage or disgust is caused by transections more posterior to the hypothalamus, such as mesencephalic decerebration in rats or cats, which effectively removes the entire diencephalon, including the hypothalamus and rostral structures, and rebalances the ratio of taste-elicited positive and negative affective reactions remaining as reflexes (Sherrington, 1906; Miller \& Sherrington, 1915; Grill \& Norgren, 1978b; Grill, 2006).

A few early specific lesion studies in the 1920 s to 1940 s similarly found 'chronic rage' in cats and dogs after localized lesions in rostral regions of the basal forebrain (which it is tempting to speculate might also have damaged the VP) (Fulton \& Ingraham, 1929; Spiegel et al., 1940). By the 1960s, the rough outline of a specific site for disgust induction began to emerge in the results obtained with large electrolytic lesions of the ventral forebrain region containing the LH and GP (which also probably damaged the VP) (Morgane, 1961; Teitelbaum \& Epstein, 1962). As Teitelbaum and Epstein wrote, after those large LH lesions (which probably intruded into the VP), a rat 'actively resists having milk placed in its mouth by a medicine dropper, and it does not swallow the milk once it is there', but instead 'does engage in the same paw-waving and wiping, chin-rubbing, poor grooming and rejection (as) when very bitter quinine ( $1 \%$ weight/volume is put in its mouth. This suggests that mouth contact with food and water is highly aversive to a rat with lateral (hypothalamic) lesions during this stage' (Teitelbaum \& Epstein, 1962). However, subsequent studies using smaller and more precise lesions suggested further that disgust was only produced by damage to the anterior part of the greater LH region (i.e. the portion of the LH that borders upon the posterior half of the VP identified here), which again possibly intruded into the VP (Schallert \& Whishaw, 1978; Stellar et al., 1979). The same rats with anterior lesions that showed disgust reactions to food also showed antisocial behavior towards other rats; they 'actively rejected the normal (other rat) by pushing it away or by kicking it away in a stereotyped manner' (p.733), rather than approaching and positively engaging as control rats did. In contrast, damage to the posterior portion of the $\mathrm{LH}$ failed to produce disgust (producing only aphagia without aversion to tastes, similarly to LH lesions here) or antisocial behavior (Schallert \& Whishaw, 1978).

The disgust lesion site was moved entirely out of the LH proper, and more anterolaterally towards the VP, on the basis of the results of an earlier study in our laboratory by Cromwell (Cromwell \& Berridge, 1993). Cromwell mapped excitotoxin lesions that released negative disgust reactions to sucrose, and was the first to report that the disgust release site was actually not in the LH at all, but rather more anteriorly and laterally in the VP or substantia innominata (Cromwell \& Berridge, 1993). The VP was further highlighted for disgust pharmacologically by Shimura et al. (2006), who reported that GABA agonist microinjections in unspecified regions of the VP similarly produced excessive gape reactions to sucrose. Finally, our present results suggest that the disgust release site for both pharmacological microinjections and excitotoxin lesions can be narrowed further to the posterior half of the VP, and is essentially identical to the VP hedonic hotspot for liking enhancements. In retrospect, it seems reasonable to entertain the explanatory hypothesis that all of the earlier ablation, lesion and pharmacological studies described above that induced intense disgust or rage reactions may have released negative affects by impinging on the same site: the hotspot in the posterior half of the VP.

In contrast, lesions in the NAc have never been reported to induce either eating deficits or a major shift towards negative affect (Koob et al., 1978; Kelley \& Stinus, 1985; Ramaswamy et al., 1998). Instead, only mild, or no, alterations in eating patterns or sucrose preference have been found (Koob et al., 1978; Kelley \& Stinus, 1985; Ramaswamy et al., 1998). Although NAc lesions may effectively impair the rewarding impact of some drugs of abuse (Koob et al., 1978; Zito et al., 1985; Bardo, 1998), NAc damage has remarkably little impact on the capacity for natural sensory pleasures, such as food, or on motivation to consume natural rewards. Our results confirm reports that NAc lesions do not induce intense negative affect or even suppress the positive hedonic impact of sucrose. We show that this conclusion applies even to lesions that specifically target the hedonic hotspot in the rostrodorsal quadrant of the medial shell, which is capable of generating opioid/endocannabinoid hedonic enhancements. 


\section{Relationship with theories of positive vs. negative affect: one or two dimensions?}

Two major views exist in psychology regarding whether affect is best described as a single dimension (e.g. a line from a positive pole to a negative pole) or as two separate dimensions (one dimension for positive affect and an independent dimension for negative affect) (Norris et al., 2010). The one-dimensional view posits every affective reaction to be a point along a single line: intense pleasant reactions are at one end, intense unpleasant reactions are at the opposite end, and neutrality is in the middle (Wundt, 1904; Young, 1918; Cacioppo et al., 1997; Feldman Barrett \& Russell, 1999; Russell \& Carroll, 1999; Kuppens et al., 2013). An implication for the brain of the one-dimensional view is that a single affective brain mechanism or circuit could, in principle, generate all pleasant or unpleasant reactions via particular neural activation intensities or states. The two-dimensional view suggests instead that the positive affect dimension is separate and orthogonal to the negative affect dimension, so that the two could be depicted as a positive $x$-axis vs. a negative $y$-axis forming a plane of intersection, in which all affective reactions are placed as two-dimensional points (Gray, 1982; Berridge \& Grill, 1984; Lang, 1995; Gray \& McNaughton, 1996; Cacioppo et al., 1997; Larsen et al., 2001; Norris et al., 2010). A brain-related implication of the two-dimensional view is that neural mechanisms for positive affect are different from those for negative affect.

How do our current results on sensory disgust relate to these views? Our finding that particular VP hotspot lesions, VP inhibitions and NAc inhibitions producing intense disgust reactions also simultaneously reduced positive liking reactions to sucrose fits best, at first sight, with the one-dimensional view. According to the onedimensional view, any increase in negative affect is necessarily also a decrease in positive affect. On the other hand, reciprocal inhibition between positive and negative mechanisms has also been posited by several advocates of the two-dimensional view (Gray, 1982; Berridge \& Grill, 1984; Lang, 1995; Gray \& McNaughton, 1996; Cacioppo et al., 1997; Larsen et al., 2001; Norris et al., 2010). If reciprocal inhibition is allowed between the two dimensions, then our reciprocal change results become more ambiguous. They could fit with the two-dimensional view, on the assumption that excessive disgust activation results in activation of the negative dimension that is intense enough to produce reciprocal inhibition of the positive dimension's expression.

According to the two-dimensional view, negative affect can change independently of positive affect, and both positive and negative affect could exist at the same time. Our results did show a relatively univalent non-reciprocal or two-dimensional change in affect after damage to a larger region of the VP outside the hotspot, LH, and/or extended amygdala. Those lesions reduced the number of positive 'liking' reactions elicited by sucrose (often producing aphagia too), but did not produce detectable 'disgust' reactions. However, according to the one-dimensional view, those lesions could have produced a mild change along a universal dimension sufficient to reduce positive hedonic impact but not to cross the neutrality midpoint into negative territory. In either case, it remains unclear mechanistically whether this selective positive suppression was truly caused by damage to anatomical zones outside the VP, or was caused by the spread of milder damage into the VP hotspot (i.e. $<65 \%$ ). Finally, a two-dimensional view probably best fits the Jacksonian-style interpretation described above, in which posterior VP damage is conceived to disrupt a mechanism of positive affect, so releasing a separate negative disgust mechanism from reciprocal inhibition or hierarchical suppression.

In the end, our current results are not conclusive for the onedimensional vs. two-dimensional debate. Future identification of a separate forebrain generator for negative disgust would support a two-dimensional or two-mechanism view, whereas a potential future finding that the posterior VP generates both liking and disgust via different modes would better support a one-dimensional or singlemechanism view.

\section{Relationship with other forms of disgust}

Human disgust spans several levels of psychological complexity, from simple sensory disgust in reaction to a nasty taste or smell as studied here, to contamination disgust in reaction to the sight of excrement, bloody bodily wounds, or particular sexual acts, to moral disgust in reaction to horrific unfairness or atrocity (Rozin \& Fallon, 1987; Schnall et al., 2008; Chapman \& Anderson, 2012). Sensory and higher levels of disgust are distinguishable psychologically and perhaps even in facial expressions (Rozin et al., 1994). However, the facial expressions do overlap between sensory and higher levels of disgust.

Most strikingly, both sensory and higher levels of disgust have been shown to activate overlapping patterns of brain circuitry in functional magnetic resonance imaging studies (Small et al., 1999; Zald \& Pardo, 2000; Zald et al., 2002; Calder, 2003; Zald, 2003; Calder et al., 2007; Mataix-Cols et al., 2008; von dem Hagen et al., 2009). Neuroimaging and electrophysiological studies have implicated particular roles in disgust for the subcortical VP and GP, the neostriatum and NAc, and the anterior insula cortex and cingulate cortex (Calder et al., 2001, 2007; Heining et al., 2003; Mataix-Cols et al., 2008; Shabel et al., 2011; Borg et al., 2012, 2014; Chapman \& Anderson, 2012; Klucken et al., 2012). Within the VP in particular, the rostral half has been reported to be activated by disgusting images of food, whereas the caudal half has been reported to be activated by pleasant food images, a difference that seems to be compatible with the notion that caudal VP dysfunction might impair positive hedonic reactions to release negative disgust generated elsewhere (and perhaps involving the rostral VP) (Beaver et al., 2006; Calder et al., 2007).

Sensory disgust in response to taste has been suggested to be the prototypical form and evolutionary origin of disgust, emerging first as a preadaptation to ovoid oral pathogens, and later becoming coopted into more complex levels by biological and cultural evolution, resulting in higher forms of disgust (Rozin, 2000; Rozin et al., 2008; Chapman et al., 2009; Tybur et al., 2013). Cross-talk between levels may also still occur psychologically, as when experience of a bad taste potentiates or primes subsequent judgements about moral disgust (Eskine et al., 2011; Herz, 2014).

Although it is speculative, application of our results to human psychopathology would suggest special roles for the posterior shell of the NAc and for the posterior regions of the VP as sites where localized neural dysfunctions might induce excessive sensory disgust, and even conceivably higher levels, such as contamination disgust or moral disgust. To the degree that neural circuitry overlaps to generate different levels of disgust, our findings at least pose the hypothesis that these subregions of the NAc and VP might deserve special scrutiny when more complex forms of excessive disgust occur in humans.

Some clinical evidence from human studies supports the idea that the VP may be needed for positive hedonic liking in humans, and 
that normal pleasure is replaced by anhedonia or by negative affect after VP damage. Although it is rare for a human clinical brain lesion to destroy the VP on both the left and the right sides of the brain without also destroying so much other ventral forebrain tissue that the patient becomes unable to communicate affective status, a few cases of relatively specific VP lesions do exist. For example, one patient with VP damage on both sides resulting from hypoxia was reported to become dominated by depression, hopelessness, guilt, and anhedonia (Miller et al., 2006). Drinking alcohol, which was previously abused, lost its pleasure for him, and he no longer craved other drugs of abuse that he had previously avidly consumed. However, this lesion probably did not fully destroy his VP, and perhaps this is why he was not as strongly seized by disgust as our rats seemed to be here. Instead, the patient still continued to eat and drink normally after his lesion, and even gained weight. However, affectively, as mentioned above, he was reported to become dominated by feelings of depression, hopelessness, guilt, and anhedonia (Miller et al., 2006). Another patient with GP lesions that were described as possibly extending into the VP reported an 'inability to feel emotions', and was described by analysts as having flat affect and 'a profound lack of motivation' (Vijayaraghavan et al., 2008). Furthermore, the patient was less motivated and less aroused by rewards such as pleasant food images, although still being motivated to avoid unpleasant stimuli (Vijayaraghavan et al., 2008). Although more evidence is needed, these clinical case studies seem at least to be consistent with the idea that damage to the VP impairs both positive affect and motivation for rewards in humans, and possibly releases excessive negative affect.

\section{Conclusion}

Overall, our data suggest that the NAc segregates the medial shell into separate zones for generating positive hedonic enhancement (rostral half of the medial shell) and release of excessive negative disgust or fear induced by temporary pharmacological GABA inactivations (caudal half of the medial shell). In contrast, the VP seems to combine excessive disgust release and positive enhancement of pleasure in the same caudal hotspot in the posterior VP. Furthermore, the VP posterior site appears to be unique as the only brain site where lesions that destroy neurons (as well as GABAergic inactivation of neurons) produce intense disgust. That same VP site is also a hotspot for hedonic enhancement. These results help to advance our understanding of how excessive negative affect, in the form of an abnormally intense sensory disgust reaction, is produced by localized brain dysfunction.

\section{Acknowledgements}

This research was supported by grants MH63649 and DA015188 from the NIH.

\section{Abbreviations}

ACSF, artificial cerebrospinal fluid; AP, anteroposterior; DV, dorsoventral; GP, globus pallidus; LH, lateral hypothalamus; ML, mediolateral; NAc, nucleus accumbens; PB, phosphate buffer; SLEA, sublenticular extended amygdala; VP, ventral pallidum.

\section{References}

Ambroggi, F., Ghazizadeh, A., Nicola, S.M. \& Fields, H.L. (2011) Roles of nucleus accumbens core and shell in incentive-cue responding and behavioral inhibition. J. Neurosci., 31, 6820-6830.
Baldo, B. \& Kelley, A. (2007) Discrete neurochemical coding of distinguishable motivational processes: insights from nucleus accumbens control of feeding. Psychopharmacology, 191, 439-459.

Bard, P. (1934) On emotional expression after decortication, with some remarks on certain theoretical views. Psychol. Rev., 41, 309-329.

Bardo, M.T. (1998) Neuropharmacological mechanisms of drug reward: beyond dopamine in the nucleus accumbens. Crit. Rev. Neurobiol., 12, 37-67.

Basso, A.M. \& Kelley, A.E. (1999) Feeding induced by GABA(A) receptor stimulation within the nucleus accumbens shell: regional mapping and characterization of macronutrient and taste preference. Behav. Neurosci., 113, 324-336.

Beaver, J., Lawrence, A., van Ditzhuijzen, J., Davis, M., Woods, A. \& Calder, A. (2006) Individual differences in reward drive predict neural responses to images of food. J. Neurosci., 26, 5160-5166.

Bengtson, C.P. \& Osborne, P.B. (2000) Electrophysiological properties of cholinergic and noncholinergic neurons in the ventral pallidal region of the nucleus basalis in rat brain slices. J. Neurophysiol., 83, 2649-2660.

Berridge, K.C. (2000) Measuring hedonic impact in animals and infants: microstructure of affective taste reactivity patterns. Neurosci. Biobehav. R., 24, 173-198.

Berridge, K.C. \& Grill, H.J. (1984) Isohedonic tastes support a two-dimensional hypothesis of palatability. Appetite, 5, 221-231.

Besson, M., Belin, D., McNamara, R., Theobald, D.E., Castel, A., Beckett, V.L., Crittenden, B.M., Newman, A.H., Everitt, B.J., Robbins, T.W. \& Dalley, J.W. (2010) Dissociable control of impulsivity in rats by dopamine $\mathrm{d} 2 / 3$ receptors in the core and shell subregions of the nucleus accumbens. Neuropsychopharmacology, 35, 560-569.

Borg, C., de Jong, P.J., Renken, R.J. \& Georgiadis, J.R. (2012) Disgust trait modulates frontal-posterior coupling as a function of disgust domain. Soc. Cogn. Affect. Neur., 8, 351-358.

Borg, C., de Jong, P.J. \& Georgiadis, J.R. (2014) Subcortical BOLD responses during visual sexual stimulation vary as a function of implicit porn associations in women. Soc. Cogn. Affect. Neur., 9, 158-166.

Cacciapaglia, F., Saddoris, M.P., Wightman, R.M. \& Carelli, R.M. (2012) Differential dopamine release dynamics in the nucleus accumbens core and shell track: distinct aspects of goal-directed behavior for sucrose. Neuropharmacology, 62, 2050-2056.

Cacioppo, J.T., Gardner, W.L. \& Berntson, G.G. (1997) Beyond bipolar conceptualizations and measures: the case of attitudes and evaluative space. Pers. Soc. Psychol. Rev., 1, 3-25.

Calder, A.J. (2003) Disgust discussed. Ann. Neurol., 53, 427-428.

Calder, A.J., Lawrence, A.D. \& Young, A.W. (2001) Neuropsychology of fear and loathing. Nat. Rev. Neurosci., 2, 352-363.

Calder, A., Beaver, J., Davis, M., van Ditzhuijzen, J., Keane, J. \& Lawrence, A. (2007) Disgust sensitivity predicts the insula and pallidal response to pictures of disgusting foods. Eur. J. Neurosci., 25, 3422-3428.

Cannon, W.B. (1927) The James-Lange theory of emotion: a critical examination and an alternative theory. Am. J. Psychol., 39, 10-124.

Carlezon, W.A. Jr. \& Thomas, M.J. (2009) Biological substrates of reward and aversion: a nucleus accumbens activity hypothesis. Neuropharmacology, 56(Suppl 1), 122-132.

Castro, D.C. \& Berridge, K.C. (2014) Opioid hedonic hotspot in nucleus accumbens shell: mu, delta, and dappa maps for enhancement of sweetness 'liking' and 'wanting'. J. Neurosci., 34, 4239-4250.

Chapman, H.A. \& Anderson, A.K. (2012) Understanding disgust. Ann. NY Acad. Sci., 1251, 62-76.

Chapman, H., Kim, D., Susskind, J. \& Anderson, A. (2009) In bad taste: evidence for the oral origins of moral disgust. Science, 323, 1222-1226.

Cisler, J.M., Olatunji, B.O. \& Lohr, J.M. (2009) Disgust, fear, and the anxiety disorders: a critical review. Clin. Psychol. Rev., 29, 34-46.

Cromwell, H.C. \& Berridge, K.C. (1993) Where does damage lead to enhanced food aversion: the ventral pallidum/substantia innominata or lateral hypothalamus? Brain Res., 624, 1-10.

Cromwell, H.C. \& Berridge, K.C. (1994) Mapping of globus pallidus and ventral pallidum lesions that produce hyperkinetic treading. Brain Res., 668, $16-29$.

Cromwell, H.C. \& Berridge, K.C. (1996) Implementation of action sequences by a neostriatal site: a lesion mapping study of grooming syntax. J. Neurosci., 16, 3444-3458.

Eskine, K.J., Kacinik, N.A. \& Prinz, J.J. (2011) A bad taste in the mouth: gustatory disgust influences moral judgment. Psychol. Sci., 22, 295-299.

Faure, A., Richard, J.M. \& Berridge, K.C. (2010) Desire and dread from the nucleus accumbens: cortical glutamate and subcortical GABA differentially generate motivation and hedonic impact in the rat. PLoS One, 5, e11223. 
Feldman Barrett, L. \& Russell, J.A. (1999) Structure of current affect. Curr. Dir. Psychol. Sci., 8, 10-14.

Fluharty, S.J. \& Grill, H.J. (1981) Taste reactivity of lateral hypothalamic lesioned rats: effects of deprivation and tube feeding. Neurosci. Abstr., 7, 29.

Fulton, J.F. \& Ingraham, F.D. (1929) Emotional disturbances following experimental lesions of the base of the brain (pre-chiasmal). Am. J. Physiol., 90, 353.

Gray, J.A. (1982) The neuropsychology of anxiety - an inquiry into the functions of the septo-hippocampal system. Behav. Brain Sci., 5, 469484.

Gray, J.A. \& McNaughton, N. (1996) The neuropsychology of anxiety: reprise. Nebr. Sym. Motiv., 43, 61-134.

Grill, H.J. (2006) Distributed neural control of energy balance: contributions from hindbrain and hypothalamus. Obesity (Silver Spring), 14(Suppl 5), 216S-221S

Grill, H.J. \& Norgren, R. (1978a) The taste reactivity test. I. Mimetic responses to gustatory stimuli in neurologically normal rats. Brain Res., 143, 263-279.

Grill, H.J. \& Norgren, R. (1978b) The taste reactivity test. II. Mimetic responses to gustatory stimuli in chronic thalamic and chronic decerebrate rats. Brain Res., 143, 281-297.

Groenewegen, H.J., Berendse, H.W. \& Haber, S.N. (1993) Organization of the output of the ventral striatopallidal system in the rat: ventral pallidal efferents. Neuroscience, 57, 113-142.

Gundersen, H.J. (2002) The smooth fractionator. J. Microsc., 207, 191-210.

Gundersen, H.J., Bagger, P., Bendtsen, T.F., Evans, S.M., Korbo, L., Marcussen, N., Moller, A., Nielsen, K., Nyengaard, J.R., Pakkenberg, B., Sorensen, F.B., Vesterby, A. \& West, M.J. (1988) The new stereological tools: disector, fractionator, nucleator and point sampled intercepts and their use in pathological research and diagnosis. APMIS, 96, 857-881.

von dem Hagen, E.A., Beaver, J.D., Ewbank, M.P., Keane, J., Passamonti, L., Lawrence, A.D. \& Calder, A.J. (2009) Leaving a bad taste in your mouth but not in my insula. Soc. Cogn. Affect. Neur., 4, 379-386.

Hayes, C.J., Stevenson, R.J. \& Coltheart, M. (2007) Disgust and Huntington's disease. Neuropsychologia, 45, 1135-1151.

Heimer, L., Van Hoesen, G.W., Trimble, M. \& Zahm, D.S. (2008) Anatomy of Neuropsychiatry: The New Anatomy of the Basal Forebrain and its Implications for Neuropsychiatric Illness. Elsevier/Academic Press, Amsterdam

Heining, M., Young, A.W., Ioannou, G., Andrew, C.M., Brammer, M.J., Gray, J.A. \& Phillips, M.L. (2003) Disgusting smells activate human anterior insula and ventral striatum. Ann. NY Acad. Sci., 1000, 380-384.

Herz, R.S. (2014) Verbal priming and taste sensitivity make moral transgressions gross. Behav. Neurosci., 128, 20-28.

Hjelmstad, G.O., Xia, Y., Margolis, E.B. \& Fields, H.L. (2013) Opioid modulation of ventral pallidal afferents to ventral tegmental area neurons. J. Neurosci., 33, 6454-6459.

Ho, C.Y. \& Berridge, K.C. (2013) An orexin hotspot in ventral pallidum amplifies hedonic 'liking' for sweetness. Neuropsychopharmacology, 38, 1655-1664.

Hoebel, B.G. \& Thompson, R.D. (1969) Aversion to lateral hypothalamic stimulation caused by intragastric feeding or obesity. J. Comp. Physiol. Psych., 68, 536-543.

Hughlings Jackson, J. (Ed.) (1958) Selected Writings of John Hughlings Jackson. Staples Press, London.

Inui, T., Shimura, T. \& Yamamoto, T. (2007) The role of the ventral pallidum GABAergic system in conditioned taste aversion: effects of microinjections of a GABAA receptor antagonist on taste palatability of a conditioned stimulus. Brain Res., 1164, 117-124.

Johnson, P.I., Stellar, J.R. \& Paul, A.D. (1993) Regional reward differences within the ventral pallidum are revealed by microinjections of a mu opiate receptor agonist. Neuropharmacology, 32, 1305-1314.

Johnson, S.A., Stout, J.C., Solomon, A.C., Langbehn, D.R., Aylward, E.H., Cruce, C.B., Ross, C.A., Nance, M., Kayson, E., Julian-Baros, E., Hayden, M.R., Kieburtz, K., Guttman, M., Oakes, D., Shoulson, I., Beglinger, L., Duff, K., Penziner, E. \& Paulsen, J.S. (2007) Beyond disgust: impaired recognition of negative emotions prior to diagnosis in Huntington's disease. Brain, 130, 1732-1744

Kelley, A.E. \& Stinus, L. (1985) Disappearance of hoarding behavior after 6-hydroxydopamine lesions of the mesolimbic dopamine neurons and its reinstatement with L-dopa. Behav. Neurosci., 99, 531-545.

Kelley, A.E., Baldo, B.A., Pratt, W.E. \& Will, M.J. (2005) Corticostriatalhypothalamic circuitry and food motivation: integration of energy, action and reward. Physiol. Behav., 86, 773-795.
Klucken, T., Schweckendiek, J., Koppe, G., Merz, C.J., Kagerer, S., Walter, B., Sammer, G., Vaitl, D. \& Stark, R. (2012) Neural correlates of disgustand fear-conditioned responses. Neuroscience, 201, 209-218.

Koob, G.F., Riley, S.J., Smith, S.C. \& Robbins, T.W. (1978) Effects of 6-hydroxydopamine lesions of the nucleus accumbens septi and olfactory tubercle on feeding, locomotor activity, and amphetamine anorexia in the rat. J. Comp. Physiol. Psych., 92, 917-927.

Krause, M., German, P.W., Taha, S.A. \& Fields, H.L. (2010) A pause in nucleus accumbens neuron firing is required to initiate and maintain feeding. J. Neurosci., 30, 4746-4756.

Kuppens, P., Tuerlinckx, F., Russell, J.A. \& Barrett, L.F. (2013) The relation between valence and arousal in subjective experience. Psychol. Bull., 139, 917-940.

Lang, P.J. (1995) The emotion probe - studies of motivation and attention. Am. Psychol., 50, 372-385.

Larsen, J.T., McGraw, A.P. \& Cacioppo, J.T. (2001) Can people feel happy and sad at the same time? J. Pers. Soc. Psychol., 81, 684-696.

Mahler, S.V., Smith, K.S. \& Berridge, K.C. (2007) Endocannabinoid hedonic hotspot for sensory pleasure: anandamide in nucleus accumbens shell enhances 'liking' of a sweet reward. Neuropsychopharmacology, 32 2267-2278.

Mahler, S.V., Vazey, E.M., Beckley, J.T., Keistler, C.R., McGlinchey, E.M., Kaufling, J., Wilson, S.P., Deisseroth, K., Woodward, J.J. \& Aston-Jones, G. (2014) Designer receptors show role for ventral pallidum input to ventral tegmental area in cocaine seeking. Nat. Neurosci., 17, 577-585

Maidment, N.T., Brumbaugh, D.R., Rudolph, V.D., Erdelyi, E. \& Evans, C.J. (1989) Microdialysis of extracellular endogenous opioid peptides from rat brain in vivo. Neuroscience, 33, 549-557.

Mataix-Cols, D., An, S.K., Lawrence, N.S., Caseras, X., Speckens, A., Giampietro, V., Brammer, M.J. \& Phillips, M.L. (2008) Individual differences in disgust sensitivity modulate neural responses to aversive/disgusting stimuli. Eur. J. Neurosci., 27, 3050-3058.

McFarland, K. \& Kalivas, P.W. (2001) The circuitry mediating cocaineinduced reinstatement of drug-seeking behavior. J. Neurosci., 21, 86558663

McFarland, K., Davidge, S.B., Lapish, C.C. \& Kalivas, P.W. (2004) Limbic and motor circuitry underlying footshock-induced reinstatement of cocaine-seeking behavior. J. Neurosci., 24, 1551-1560.

Meredith, G.E., Baldo, B.A., Andrezjewski, M.E. \& Kelley, A.E. (2008) The structural basis for mapping behavior onto the ventral striatum and its subdivisions. Brain Struct. Funct., 213, 17-27.

Miller, F.R. \& Sherrington, C.S. (1915) Some observations on the buccopharyngeal stage of reflex deglutition in the cat. Q. J. Exp. Physiol., 9, 147-186.

Miller, J., Vorel, S., Tranguch, A., Kenny, E., Mazzoni, P., van Gorp, W. \& Kleber, H. (2006) Anhedonia after a selective bilateral lesion of the globus pallidus. Am. J. Psychiat., 163, 786-788.

Morgane, P.J. (1961) Alterations in feeding and drinking behavior of rats with lesions of the globus pallidi. Am. J. Physiol., 201, 420-428.

Murphy, F.C., Nimmo-Smith, I. \& Lawrence, A.D. (2003) Functional neuroanatomy of emotions: a meta-analysis. Cogn. Affect. Behav. Ne., 3, 207233.

Norgren, R. \& Leonard, C.M. (1973) Ascending central gustatory pathways. J. Comp. Neurol., 150, 217-237.

Norris, C.J., Gollan, J., Berntson, G.G. \& Cacioppo, J.T. (2010) The current status of research on the structure of evaluative space. Biol. Psychol., 84, $422-436$.

Olatunji, B.O., Cisler, J., McKay, D. \& Phillips, M.L. (2010) Is disgust associated with psychopathology? Emerging research in the anxiety disorders. Psychiat. Res., 175, 1-10.

Paxinos, G. \& Watson, C. (2008) The Rat Brain in Stereotaxic Coordinates, 6th Edn. Academic Press, London, UK.

Peciña, S. \& Berridge, K.C. (2005) Hedonic hot spot in nucleus accumbens shell: where do mu-opioids cause increased hedonic impact of sweetness? J. Neurosci., 25, 11777-11786.

Pfaffmann, C., Norgren, R. \& Grill, H.J. (1977) Sensory affect and motivation. Ann. NY Acad. Sci., 290, 18-34.

Ramaswamy, C., Ghosh, B. \& Vasudev, R. (1998) Regulatory role of nucleus accumbens in the ingestion of sucrose and saccharine. Indian $J$. Exp. Biol., 36, 820-823.

Resendez, S.L., Dome, M., Gormley, G., Franco, D., Nevrez, N., Hamid, A.A. \& Aragona, B.J. (2013) Mu-opioid receptors within subregions of the striatum mediate pair bond formation through parallel yet distinct reward mechanisms. J. Neurosci., 33, 9140-9149. 
Reynolds, S.M. \& Berridge, K.C. (2001) Fear and feeding in the nucleus accumbens shell: rostrocaudal segregation of GABA-elicited defensive behavior versus eating behavior. J. Neurosci., 21, 3261-3270.

Reynolds, S.M. \& Berridge, K.C. (2002) Positive and negative motivation in nucleus accumbens shell: bivalent rostrocaudal gradients for GABA-elicited eating, taste 'liking'/'disliking' reactions, place preference/avoidance, and fear. J. Neurosci., 22, 7308-7320.

Richard, J.M. \& Berridge, K.C. (2011) Nucleus accumbens dopamine/glutamate interaction switches modes to generate desire versus dread: D1 alone for appetitive eating but D1 and D2 together for fear. J. Neurosci., 31, $12866-12879$.

Richard, J.M., Castro, D.C., DiFeliceantonio, A.G., Robinson, M.J. \& Berridge, K.C. (2013a) Mapping brain circuits of reward and motivation: in the footsteps of Ann Kelley. Neurosci. Biobehav. R., 37, 1919-1931.

Richard, J.M., Plawecki, A.M. \& Berridge, K.C. (2013b) Nucleus accumbens GABAergic inhibition generates intense eating and fear that resists environmental retuning and needs no local dopamine. Eur. J. Neurosci., 37, 1789-1802.

Rocha, A. \& Kalivas, P.W. (2010) Role of the prefrontal cortex and nucleus accumbens in reinstating methamphetamine seeking. Eur. J. Neurosci., 31, 903-909.

Roitman, M.F., Wheeler, R.A. \& Carelli, R.M. (2005) Nucleus accumbens neurons are innately tuned for rewarding and aversive taste stimuli, encode their predictors, and are linked to motor output. Neuron, 45, 587-597.

Roitman, M.F., Wheeler, R.A., Tiesinga, P.H., Roitman, J.D. \& Carelli, R.M. (2010) Hedonic and nucleus accumbens neural responses to a natural reward are regulated by aversive conditioning. Learn. Memory, 17, 539-546.

Root, D.H., Fabbricatore, A.T., Ma, S., Barker, D.J. \& West, M.O. (2010) Rapid phasic activity of ventral pallidal neurons during cocaine selfadministration. Synapse, 64, 704-713.

Rozin, P. (2000) Disgust. In Lewis, M. \& Haviland-Jones, J.M. (Eds), Handbook of Emotions. Guilford, New York, pp. 637-653.

Rozin, P. \& Fallon, A.E. (1987) A perspective on disgust. Psychol. Rev., 94, 23-41.

Rozin, P. \& Haidt, J. (2013) The domains of disgust and their origins: contrasting biological and cultural evolutionary accounts. Trends Cogn. Sci., 17, 367-368.

Rozin, P., Lowery, L. \& Ebert, R. (1994) Varieties of disgust faces and the structure of disgust. J. Pers. Soc. Psychol., 66, 870-881.

Rozin, P., Haidt, J. \& McCauley, C.R. (2008) Disgust. In Lewis, M. \& Haviland, J. (Eds), Handbook of Emotions. Gilford, New York, pp. 757-776.

Russell, J.A. \& Carroll, J.M. (1999) On the bipolarity of positive and negative affect. Psychol. Bull., 125, 3-30.

Sambataro, F., Dimalta, S., Di Giorgio, A., Taurisano, P., Blasi, G., Scarabino, T., Giannatempo, G., Nardini, M. \& Bertolino, A. (2006) Preferential responses in amygdala and insula during presentation of facial contempt and disgust. Eur. J. Neurosci., 24, 2355-2362.

Schallert, T. \& Whishaw, I.Q. (1978) Two types of aphagia and two types of sensorimotor impairment after lateral hypothalamic lesions: observations in normal weight, dieted, and fattened rats. J. Comp. Physiol. Psych., 92, $720-741$.

Schnall, S., Haidt, J., Clore, G.L. \& Jordan, A.H. (2008) Disgust as embodied moral judgment. Pers. Soc. Psychol. B., 34, 1096-1109.

Sesack, S.R. \& Grace, A.A. (2010) Cortico-basal ganglia reward network: microcircuitry. Neuropsychopharmacology, 35, 27-47.

Shabel, S.J., Schairer, W., Donahue, R.J., Powell, V. \& Janak, P.H. (2011) Similar neural activity during fear and disgust in the rat basolateral amygdala. PLoS One, 6, e27797.

Sherrington, C.S. (1906) The Integrative Action of the Nervous System. C. Scribner's Sons, New York.

Shimura, T., Imaoka, H. \& Yamamoto, T. (2006) Neurochemical modulation of ingestive behavior in the ventral pallidum. Eur. J. Neurosci., 23, 1596-1604.

Small, D.M., Zald, D.H., Jones-Gotman, M., Zatorre, R.J., Pardo, J.V., Frey, S. \& Petrides, M. (1999) Human cortical gustatory areas: a review of functional neuroimaging data. NeuroReport, 10, 7-14.

Smith, K.S. \& Berridge, K.C. (2005) The ventral pallidum and hedonic reward: neurochemical maps of sucrose 'liking' and food intake. J. Neurosci., 25, 8637-8649.

Smith, K.S. \& Berridge, K.C. (2007) Opioid limbic circuit for reward: interaction between hedonic hotspots of nucleus accumbens and ventral pallidum. J. Neurosci., 27, 1594-1605.

Smith, K.S., Mahler, S.V., Pecina, S. \& Berridge, K.C. (2010) Hedonic hotspots: generating sensory pleasure in the brain. In Kringelbach, M.L. \& Berridge, K.C. (Eds), Pleasures of the Brain. Oxford University Press, Oxford, pp. 27-49.
Smith, K.S., Berridge, K.C. \& Aldridge, J.W. (2011) Disentangling pleasure from incentive salience and learning signals in brain reward circuitry. Proc. Natl. Acad. Sci. USA, 108, E255-E264.

Sorenson, C.A. \& Ellison, G.D. (1970) Striatal organization of feeding behavior in the decorticate rat. Exp. Neurol., 29, 162-174.

Spiegel, E.A., Miller, H.R. \& Oppenheimer, M.J. (1940) Forebrain and rage reactions. J. Neurophysiol., 3, 538-548.

Sprengelmeyer, R., Young, A.W., Pundt, I., Sprengelmeyer, A., Calder, A.J., Berrios, G., Winkel, R., Vollmoeller, W., Kuhn, W., Sartory, G. \& Przuntek, H. (1997) Disgust implicated in obsessive-compulsive disorder. $P$. Roy. Soc. B-Biol. Sci., 264, 1767-1773.

Steiner, J.E. (1973) The gustofacial response: observation on normal and anencephalic newborn infants. Symp. Oral Sens. Percept., 4, 254-278.

Steiner, J.E., Glaser, D., Hawilo, M.E. \& Berridge, K.C. (2001) Comparative expression of hedonic impact: affective reactions to taste by human infants and other primates. Neurosci. Biobehav. R., 25, 53-74.

Stellar, J.R., Brooks, F.H. \& Mills, L.E. (1979) Approach and withdrawal analysis of the effects of hypothalamic stimulation and lesions in rats. J. Comp. Physiol. Psych., 93, 446-466.

Stratford, T.R. (2005) Activation of feeding-related neural circuitry after unilateral injections of muscimol into the nucleus accumbens shell. Brain Res., 1048, 241-250.

Stratford, T.R. \& Kelley, A.E. (1997) GABA in the nucleus accumbens shell participates in the central regulation of feeding behavior. J. Neurosci., 17, 4434-4440.

Stratford, T.R. \& Kelley, A.E. (1999) Evidence of a functional relationship between the nucleus accumbens shell and lateral hypothalamus subserving the control of feeding behavior. J. Neurosci., 19, 1104011048

Stratford, T.R. \& Wirtshafter, D. (2012) Evidence that the nucleus accumbens shell, ventral pallidum, and lateral hypothalamus are components of a lateralized feeding circuit. Behav. Brain Res., 226, 548-554.

Swanson, L.W. (2005) Anatomy of the soul as reflected in the cerebral hemispheres: neural circuits underlying voluntary control of basic motivated behaviors. J. Comp. Neurol., 493, 122-131.

Teitelbaum, P. \& Epstein, A.N. (1962) The lateral hypothalamic syndrome: recovery of feeding and drinking after lateral hypothalamic lesions. Psychol. Rev., 69, 74-90.

Thompson, R.H. \& Swanson, L.W. (2010) Hypothesis-driven structural connectivity analysis supports network over hierarchical model of brain architecture. Proc. Natl. Acad. Sci. USA, 107, 15235-15239.

Tindell, A.J., Berridge, K.C. \& Aldridge, J.W. (2004) Ventral pallidal representation of pavlovian cues and reward: population and rate codes. J. Neurosci., 24, 1058-1069.

Tindell, A.J., Berridge, K.C., Zhang, J., Peciña, S. \& Aldridge, J.W. (2005) Ventral pallidal neurons code incentive motivation: amplification by mesolimbic sensitization and amphetamine. Eur. J. Neurosci., 22, 2617-2634.

Tindell, A.J., Smith, K.S., Pecina, S., Berridge, K.C. \& Aldridge, J.W. (2006) Ventral pallidum firing codes hedonic reward: when a bad taste turns good. J. Neurophysiol., 96, 2399-2409.

Tybur, J.M., Lieberman, D., Kurzban, R. \& DeScioli, P. (2013) Disgust: evolved function and structure. Psychol. Rev., 120, 65-84.

Vanderwolf, C.H., Kolb, B. \& Cooley, R.K. (1978) Behavior of the rat after removal of the neocortex and hippocampal formation. J. Comp. Physiol. Psych., 92, 156-175.

Vijayaraghavan, L., Vaidya, J., Humphreys, C., Beglinger, L. \& Paradiso, S. (2008) Emotional and motivational changes after bilateral lesions of the globus pallidus. Neuropsychology, 22, 412-418.

Warren, J.M., Warren, H.B. \& Akert, K. (1972) The behavior of chronic cats with lesions in the frontal association cortex. Acta Neurobiol. Exp. (Wars), 32, 361-392.

Wassum, K.M., Ostlund, S.B., Maidment, N.T. \& Balleine, B.W. (2009) Distinct opioid circuits determine the palatability and the desirability of rewarding events. Proc. Natl. Acad. Sci. USA, 106, 12512-12517.

Weygandt, M., Blecker, C.R., Schafer, A., Hackmack, K., Haynes, J.D., Vaitl, D., Stark, R. \& Schienle, A. (2012) fMRI pattern recognition in obsessive-compulsive disorder. NeuroImage, 60, 1186-1193.

Wirsig, C.R. \& Grill, H.J. (1982) Contribution of the rat's neocortex to ingestive control: I. Latent learning for the taste of sodium chloride. $J$. Comp. Physiol. Psych., 96, 615-627.

Wirtshafter, D. \& Stratford, T.R. (2010) Evidence for motivational effects elicited by activation of GABA-A or dopamine receptors in the nucleus accumbens shell. Pharmacol. Biochem. Be., 96, 342-346.

Wu, Q., Clark, M.S. \& Palmiter, R.D. (2012) Deciphering a neuronal circuit that mediates appetite. Nature, 483, 594-597. 
Wundt, W. (1904) Principles of Physiological Psychology. MacMillen, New York.

Xia, Y., Driscoll, J.R., Wilbrecht, L., Margolis, E.B., Fields, H.L. \& Hjelmstad, G.O. (2011) Nucleus accumbens medium spiny neurons target non-dopaminergic neurons in the ventral tegmental area. J. Neurosci., 31, 7811-7816.

Young, P.T. (1918) An experimental study of mixed feelings. Am. J. Psychol., 29, 237-271.

Zahm, D.S. (2006) The evolving theory of basal forebrain functional-anatomical 'macrosystems'. Neurosci. Biobehav. R., 30, 148-172.

Zahm, D.S. \& Heimer, L. (1990) Two transpallidal pathways originating in the rat nucleus accumbens. J. Comp. Neurol., 302, 437-446.

Zahm, D.S., Williams, E. \& Wohltmann, C. (1996) Ventral striatopallidothalamic projection: IV. Relative involvements of neurochemically distinct subterritories in the ventral pallidum and adjacent parts of the rostroventral forebrain. J. Comp. Neurol., 364, 340-362.
Zahm, D.S., Parsley, K.P., Schwartz, Z.M. \& Cheng, A.Y. (2013) On lateral septum-like characteristics of outputs from the accumbal hedonic 'hotspot' of Peciña and Berridge with commentary on the transitional nature of basal forebrain 'boundaries'. J. Comp. Neurol., 521, 50-68.

Zald, D.H. (2003) The human amygdala and the emotional evaluation of sensory stimuli. Brain Res. Rev., 41, 88-123.

Zald, D.H. \& Pardo, J.V. (2000) Cortical activation induced by intraoral stimulation with water in humans. Chem. Senses, 25, 267-275.

Zald, D.H., Hagen, M.C. \& Pardo, J.V. (2002) Neural correlates of tasting concentrated quinine and sugar solutions. J. Neurophysiol., 87, 10681075.

Zito, K.A., Vickers, G. \& Roberts, D.C. (1985) Disruption of cocaine and heroin self-administration following kainic acid lesions of the nucleus accumbens. Pharmacol. Biochem. Be., 23, 1029-1036. 